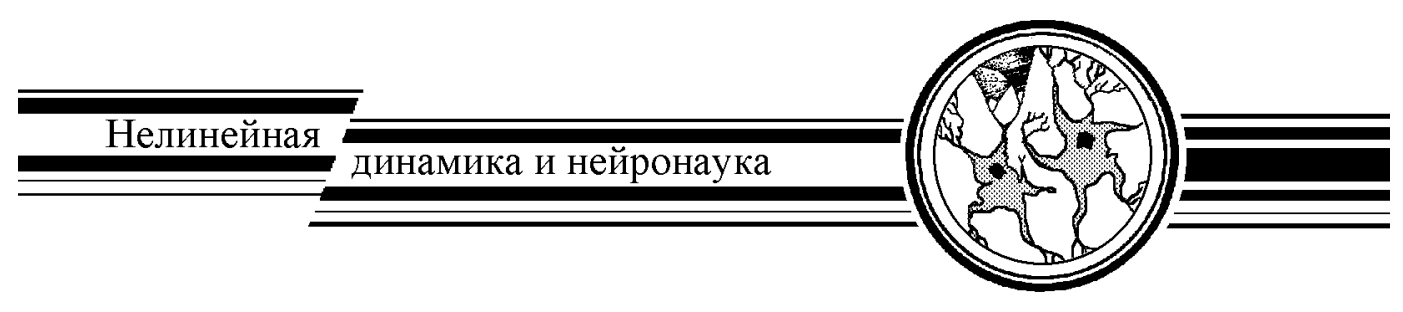

УДК 514.9:612.8

\title{
МАТЕМАТИКА СОЗНАНИЯ*
}

\section{Михаил Рабинович ${ }^{1}$, Пабло Варона ${ }^{2}$}

${ }^{1}$ BioCircuits Institute, US, UCSD, 9500 Gilman Drive, La Jolla, CA 92093-0328

${ }^{2}$ Universidad Autónoma de Madrid, C Francisco Tomás y Valiente, 11, 28049 Madrid, Spain

E-mail:mrabinovich@gmail.com; pablo.varona@uam.es

В данной слайдовой лекции мы предлагаем новую концепцию для построения математической теории когнитивных функций человека, включая сознание. Такие функции как творчество, принятие решений и предсказания, на основе анализа прошлого, описываются в рамках канонических динамических моделей в форме глобальных иерархических сетей. Блоки таких сетей кооперируются и конкурируют друг с другом за счет ингибирования. Активность сетей демонстрирует переходную цепочечную динамику, для описания которой мы используем гетероклинические структуры, представляющие в ментальном пространстве когнитивные компоненты на разных уровнях иерархии взаимодействия. Впервые мы строим систему кинетических экологических уравнений, описывающих взаимодействие эмоций и когнитивных функций на всех уровнях иерархии. Особенно это необходимо для описания разных этапов творчества. Мы исследуем кооперацию мозга человека и искусственного интеллекта на примере музыкальных импровизаций и создания «кооперативной» музыки. Например, когда робот комплектует информационные группы и на их основе рабочую память, а человек использует эмоции и интуицию для отбора. Уровень творчества оценивается по величине энтропии Колмогорова-Синая. Анализ совместного музыкального творчества человека и искусственного интеллекта может быть полезен для разных приложений, в частности, для диагностики некоторой группы психиатрических заболеваний.

Ключевые слова: Сознание как последовательный динамический процесс, ингибиторные сети мозга, иерархические группы информационных паттернов, многокомпонентные функции и группировка, последовательная динамика рабочей памяти, совместная ментальная активность робота и человека.

DOI: 10.18500/0869-6632-2017-25-3-5-51

Образец цитирования: Рабинович М., Варона П. Математика сознания // Известия вузов. Прикладная нелинейная динамика. 2017. Т. 25, № 3. С. 5-51.

*Авторская презентация лекции «Modeling of Consciousness Dynamics: Decision Making \& Creativity», озвученной на Muri Winter School 2017 «Dynamics of Multifunction Brain Networks», January 11-13, 2017, UC San Diego, US.

(c) М. Рабинович, П. Варона

Изв. вузов «ПНД», т. 25, № 3, 2017 


\title{
MATHEMATICS OF MIND
}

\author{
Mikhail Rabinovich ${ }^{1}$, Pablo Varona ${ }^{2}$ \\ ${ }^{1}$ BioCircuits Institute, US, UCSD, 9500 Gilman Drive, La Jolla, CA 92093-0328 \\ ${ }^{2}$ Universidad Autónoma de Madrid, C Francisco Tomás y Valiente, 11, 28049 Madrid, Spain \\ E-mail:mrabinovich@gmail.com; pablo.varona@uam.es
}

In this slide-lecture we formulate a novel paradigm for the mathematical description of mental functions such as consciousness, creativity, decision making and prediction of the future based on the past. Such cognitive functions are described in the framework of canonical nonlinear dynamical models that form joint global hierarchical networks. Subnetworks cooperate and compete with each other by inhibition. The suggested approach uses heteroclinic dynamics to represent transitivity and sequential interaction of different cognitive modalities at all levels of network hierarchy. For the first time we build a model of global network dynamics based on a set of kinetic ecological equations describing the interaction with emotion at each level of the hierarchy. This makes the model applicable for the description and understanding of perception, creativity and other complex cognitive processes. We discuss the creativity phenomenon, for example, in a joint «human-robot mind» considering the approximation in which the artificial partner is responsible for the binding and retrieving of multimodal perception information. The formation of chunks and the creation of working memory is a joint effort - human-robot mind. The human mind is responsible for the evaluation of the information in working memory. Creativity is estimated by Kolmogorov-Sinai entropy. As an example, we discuss joint human-robot musical improvisation, which can be generalized for many applications, in particular, in the context of artificial intelligence applications and to address several psychiatric disorders.

Keywords: Consciousness as a sequential dynamical process, inhibitory brain networks, hierarchical chunking of information patterns, multimodality and binding, working memory sequential dynamics, human-robot «joint mind».

DOI: $10.18500 / 0869-6632-2017-25-3-5-51$

Paper reference: Rabinovich M., Varona P. Mathematics of mind. Izvestiya VUZ. Applied Nonlinear Dynamics. 2017. Vol. 25, Iss. 3. P. 5-51.

Самое увлекательное - это размышлять о том, как мы мыслим.

Фольклор

Сейчас кажется очевидным, что человеческое поведение представляет собой последовательность элементарных актов - операций, приемов или процедур, сменяющих друг друга во времени. Вспомним танцы, игру на музыкальных инструментах, приготовление кофе или выступление на конференции. Любой из этих процессов, если отвлечься от механизмов генерации программы элементарных действий, легко может быть смоделирован математически с помощью цепочечных моделей. Последовательные элементы, конечно, могут быть различными. Если же мы задумаемся о том каким образом создается в мозгу программа подобного поведения, то есть как организуется смена одного метастабильного состояния цепочки другим и как формируются сами эти состояния, то задача покажется очень сложной и даже невыполнимой. Это впечатление лишь усилится, если мы попытаемся объяснить воображаемые последствия наших действий в настоящем.

Именно поэтому выглядит естественной расхожая точка зрения - интеллект и само сознание это настолько интригующие и даже мистические явления, что они недоступны для формализации и математического описания. Цель данной обзорной лекции в картинках представить альтернативную точку зрения и, если не убедить читателя, то заинтересовать его настолько, что он сам начнет размышлять, как же 
мы мыслим, а данная лекция представит ему для этого экспериментальные материалы. Мы сосредоточим внимание на недавних экспериментах, моделях и эволюционных подходах, чтобы проиллюстрировать возможность описания с помощью методов нелинейной динамики таких когнитивных явлений, как творчество, принятие решений, управление вниманием и рабочей памятью.

Сознание, как известно, теряется, когда из строя выходят или попадают под анестезию основные, или центровые структуры, наиболее плотно связанные анатомически друг с другом и, возможно, не напрямую со многими другими структурами. Сознание также пропадает, если нарушается нормальное динамическое взаимодействие между комплексами мозга. Например, когда они в результате чрезмерного возбуждения переходят в режим почти полной взаимной синхронизации, то есть в эпилептический припадок.

В последние пять-семь лет под влиянием впечатляющих экспериментальных данных, в первую очередь, исследования пространственно-временной активности мозга в процессе выполнения когнитивных функций (анализ функциональных магнитно-резонансных паттернов) практически установлено, что функциональная активность мозга это переходный процесс, к которому применимы такие динамические характеристики, как структурная устойчивость, бифуркации, энтропия КолмогороваСиная, размерность и т.д.

Считается, что сознание есть результат взаимно скоординированной (иногда еще говорят интегральной) активности большинства когнитивных структур мозга. Разные когнитивные функции выполняются разными иерархическими сетями (networks), каждая из которых объединяет большое число субструктур мозга. Подобную сеть можно рассматривать как нерегулярную дискретную решетку, активность которой представляется набором мод или возбуждений. Переходная динамика, отвечающая когнитивному процессу, есть не что иное, как последовательная смена мод в результате из взаимного подавления по принципу «конкуренция без победителя».

В английском языке помимо слова brain (мозг), есть еще слово mind, которое переводится по разному - разум, интеллект и даже сознание. Мы используем это слово в смысле «пространство когнитивных функций мозга». Для построения математической теории сознания это пространство очень естественно, нужно только удачно ввести динамические переменные.

Психологи на основании огромного количества эмпирических данных разделяют следующие стадии творчества. 1. Предварительная формулировка проблемы и подсознательное набрасывание идей. 2. Инкубационная стадия, когда отбираются наиболее интересные идеи, осознаются детали. 3. Инновационная стадия, где центральным является момент озарения, то есть бифуркация «Эврика». 4. Проверка и оценка сгенерированного решения (мысли, способа и т.д.). Здесь согласованно работают такие когнитивные нетворки, как автобиографическая память (эпизодическая и семантическая), внимание, эмоциональная поддержка, рабочая память и принятие решений. Все вместе эти нетворки образуют иерархическую сеть, динамика которой на разных стадиях решения задачи различна. От случайного блуждания (стадия 1) система переходит в режим регулярной инспекции рабочей памяти - гетероклинические циклы (стадия 2). Затем при взаимодействии рабочей памяти с квазипериодической динамикой внимания в момент «Эврика» рождается хаос или новое метастабильное состояние (стадия 3). Далее принимается решение - то ли мы получили, что нам нужно (стадия 4).

Даже такое шаржированное описание дает представление о далеко идущих возможностях применения нелинейной динамики к описанию процесса творчества и сознания в целом.

(c) М. Рабинович, П. Варона

Изв. вузов «ПНД», т. 25, № 3, 2017 


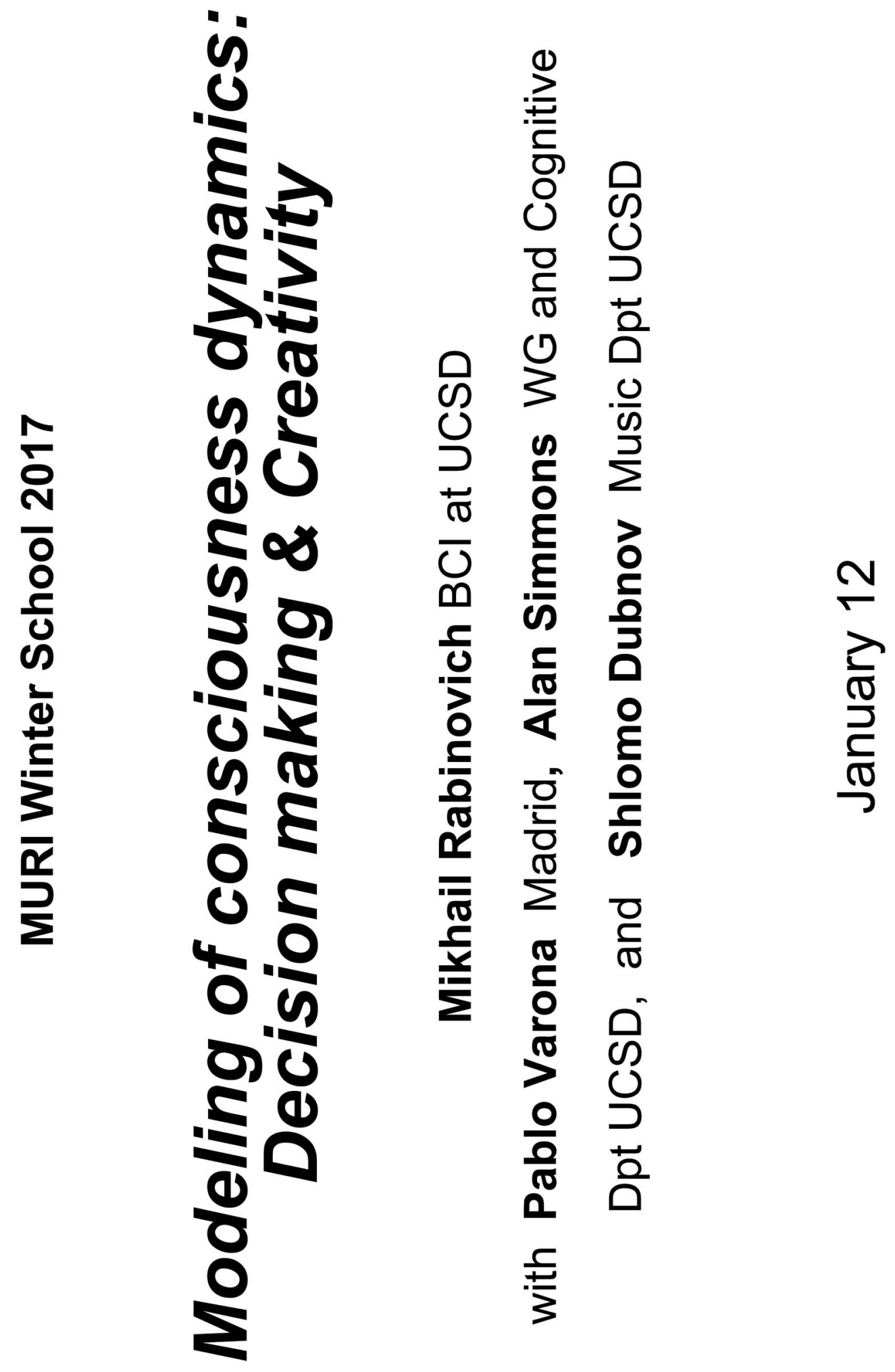

(C) М. Рабинович, П. Варона Изв. вузов «ПНД», т. 25, № 3, 2017 


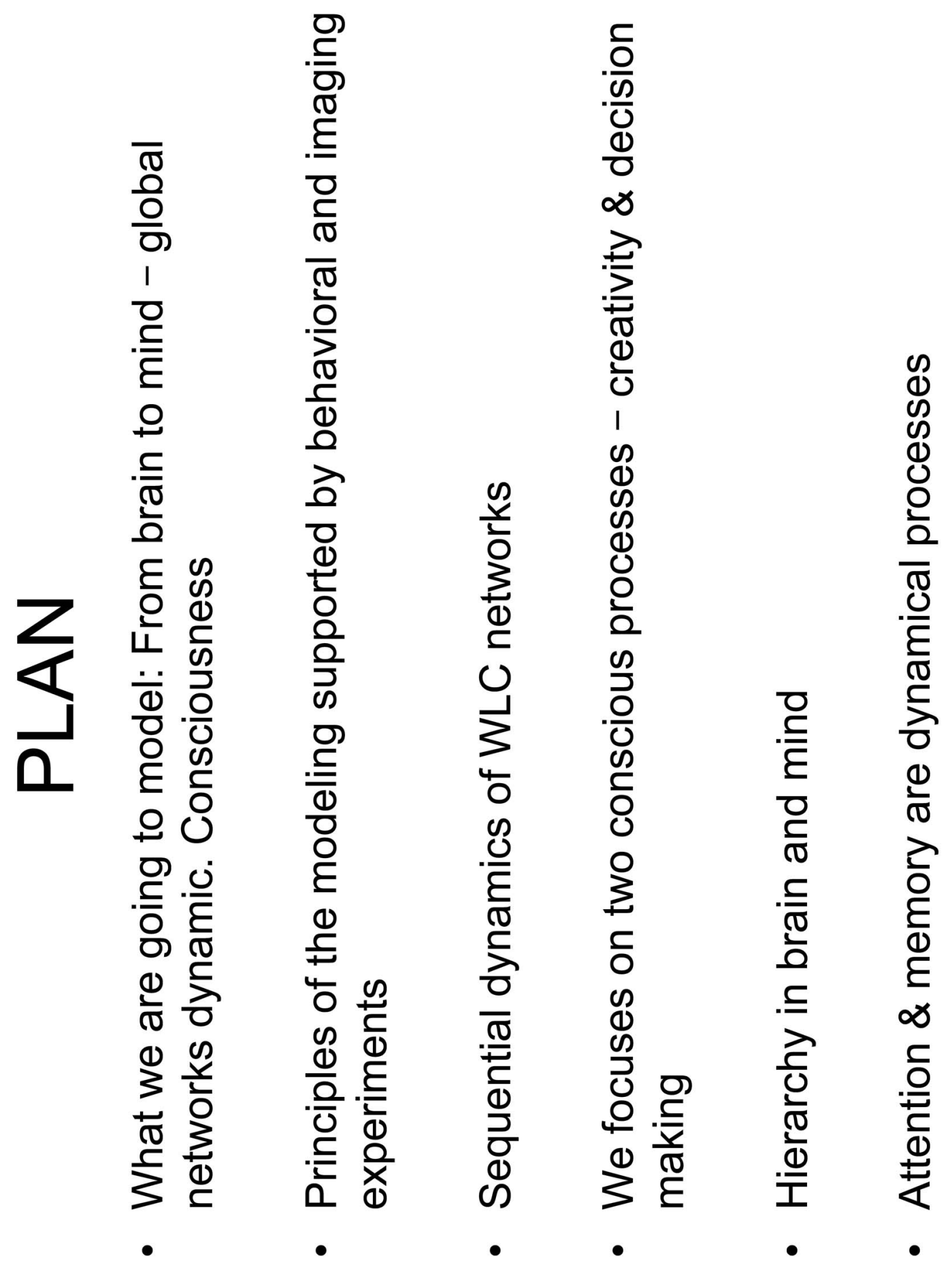




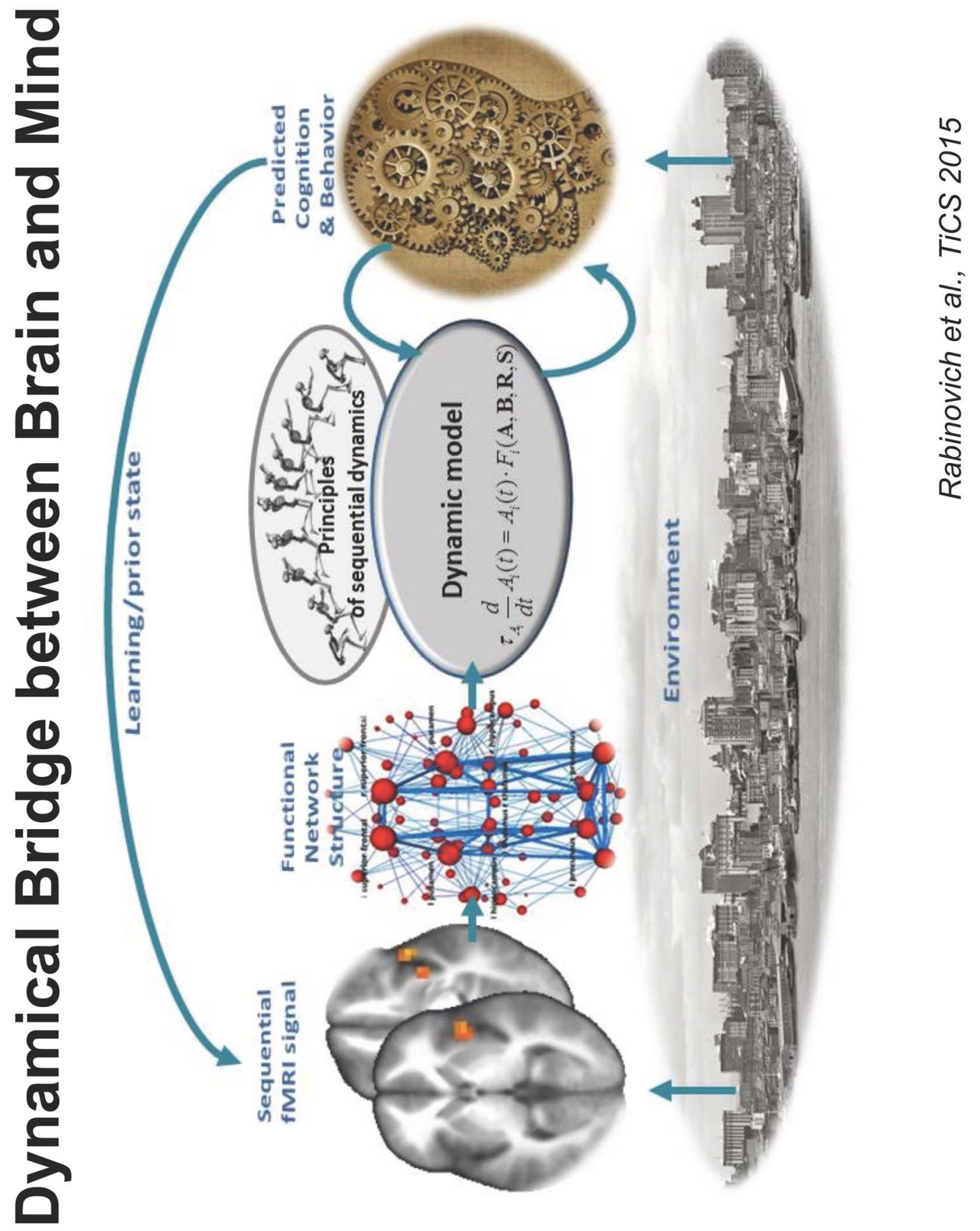

(C) М. Рабинович, П. Варона 


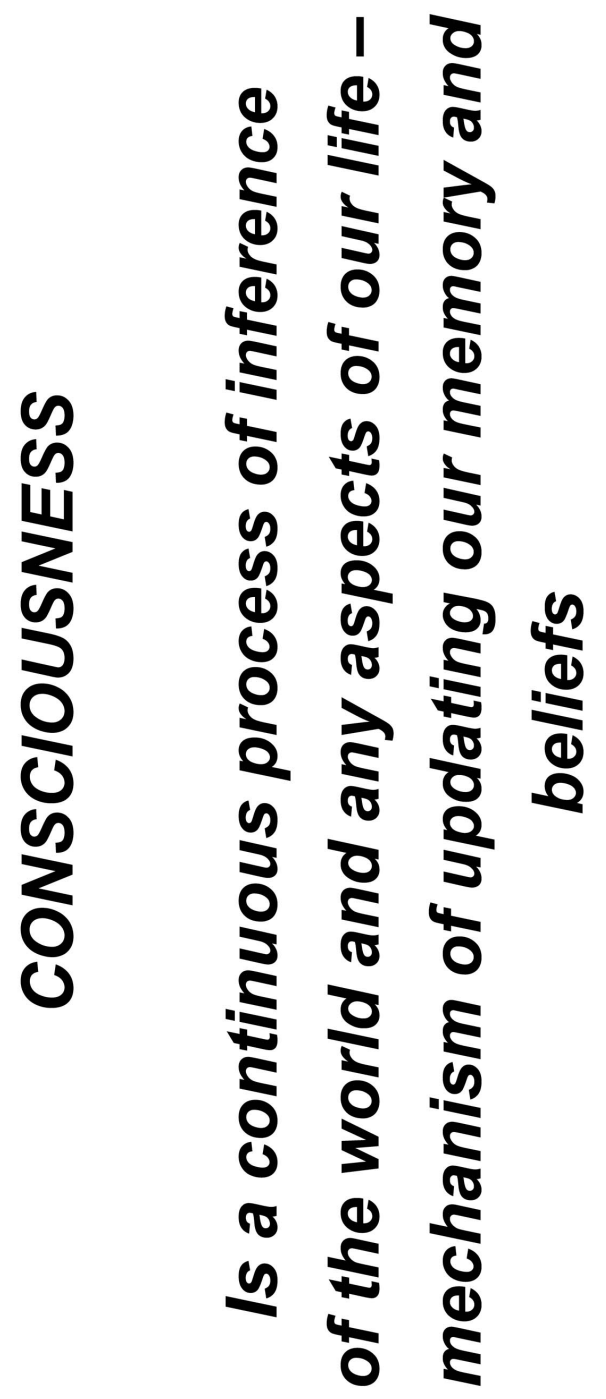




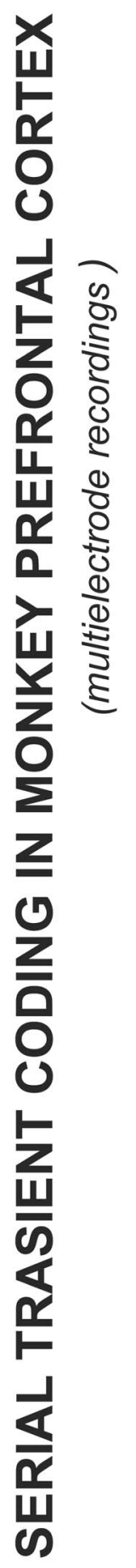

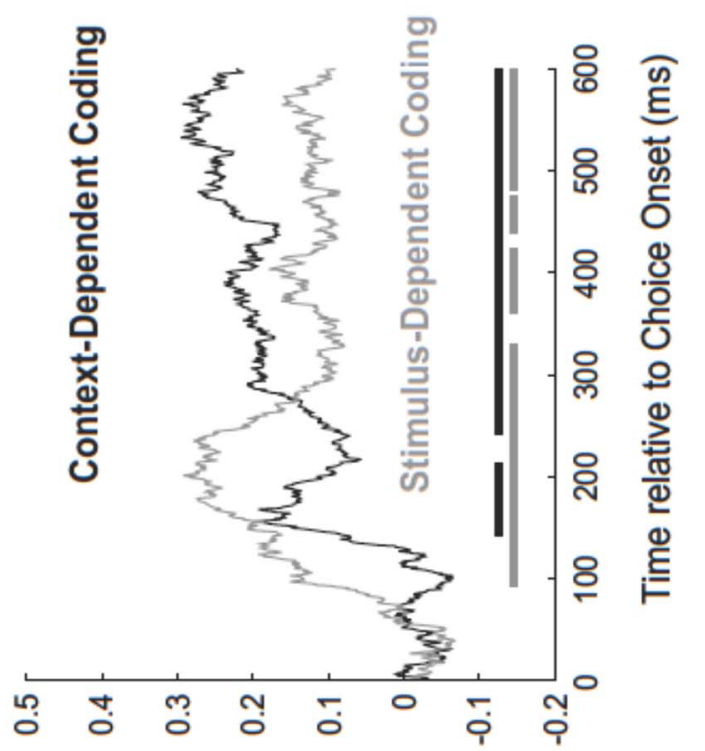

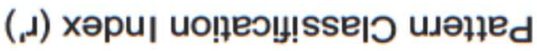

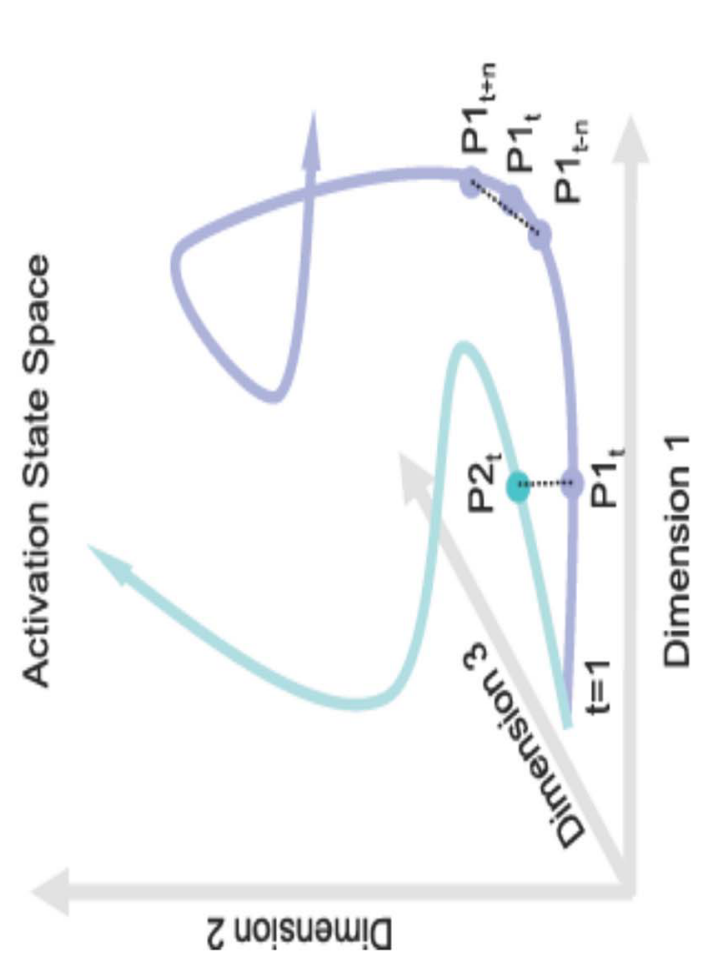

$\stackrel{\oplus}{\underline{E}} \stackrel{0}{=}$ \% 잉 흥 융 品 d 등 즘 음ำ

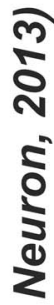
3
$\therefore$

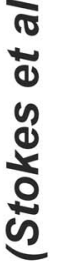
no 今. 온 ง 0 เ 융ำ ¿ ฯ โร

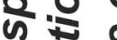
\& 政 ป ำ की 0 오 So तั ह ㅇำ ร को ठิ $\frac{0}{4} \frac{2}{2} \frac{\pi}{2}$ व ह ए 요워 方迹 อ. ฮ 

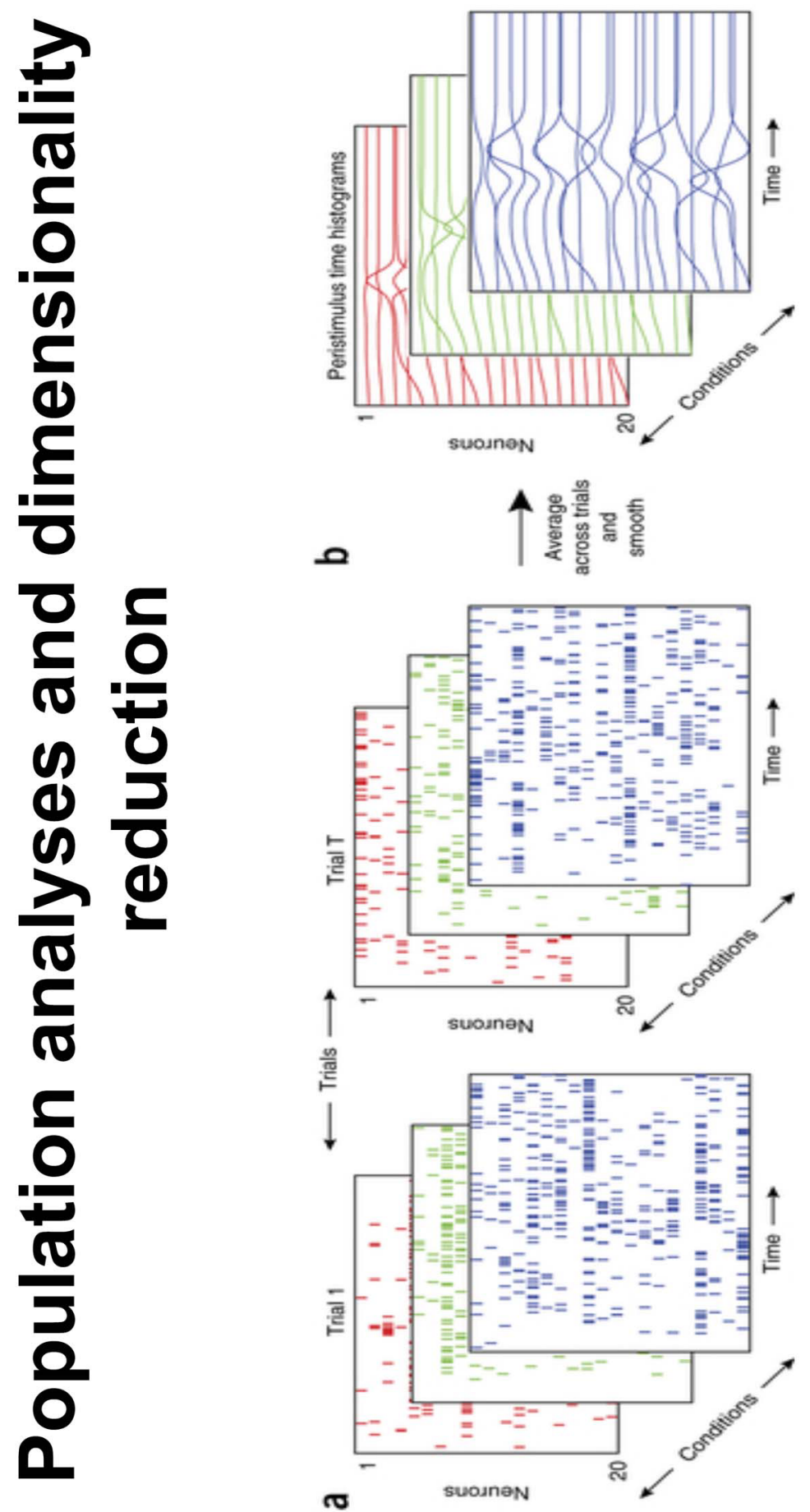

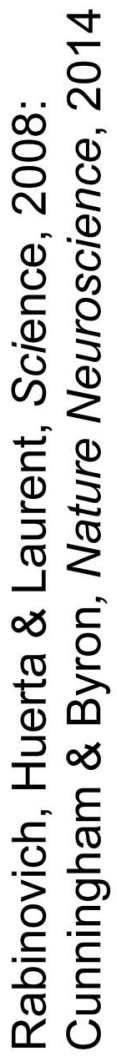

(C) М. Рабинович, П. Варона

Изв. вузов «ПНД», т. 25, № 3, 2017 

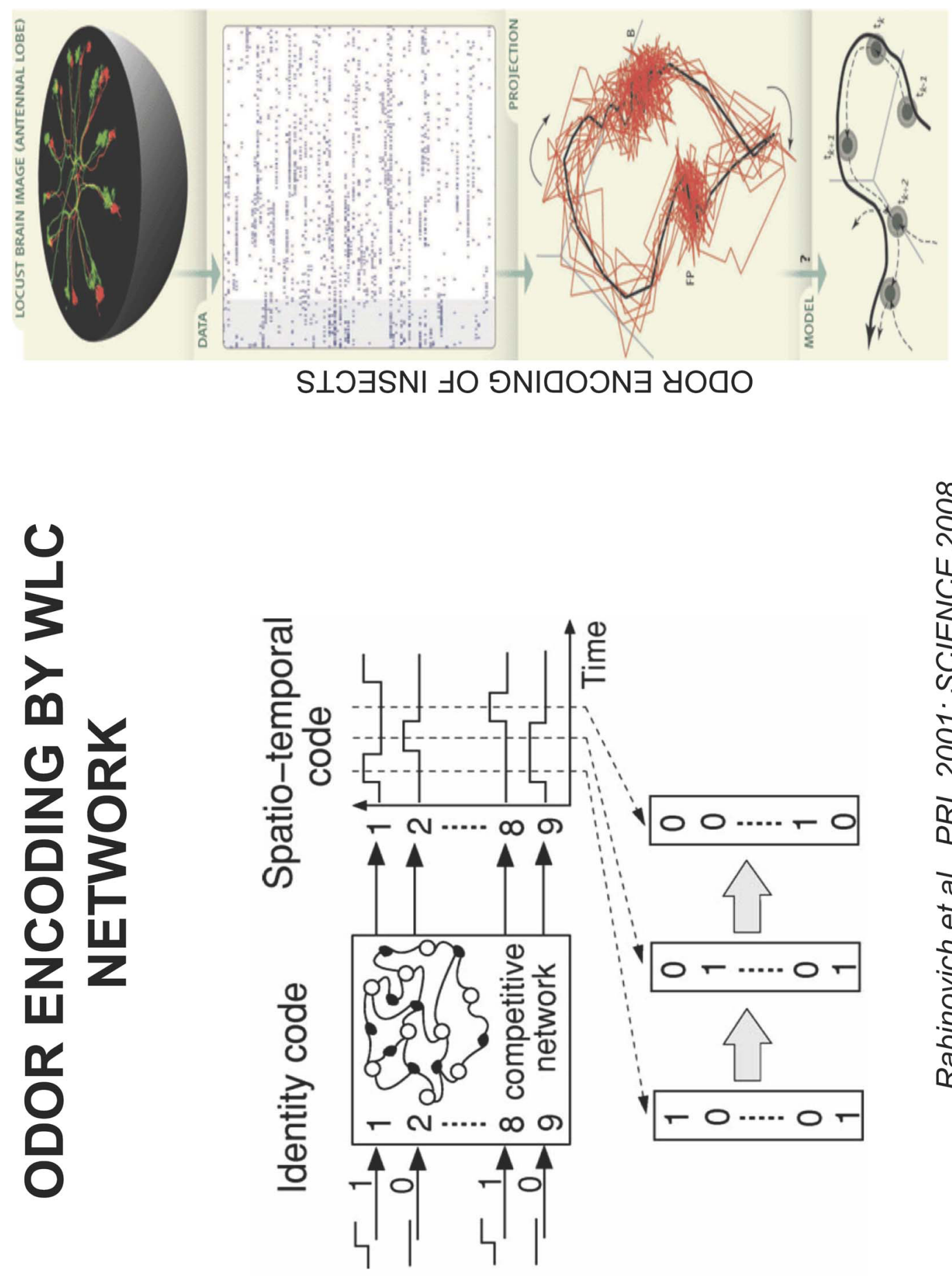

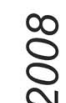

过

ำ

$\frac{1}{\alpha}$

$\frac{1}{\pi}$ 


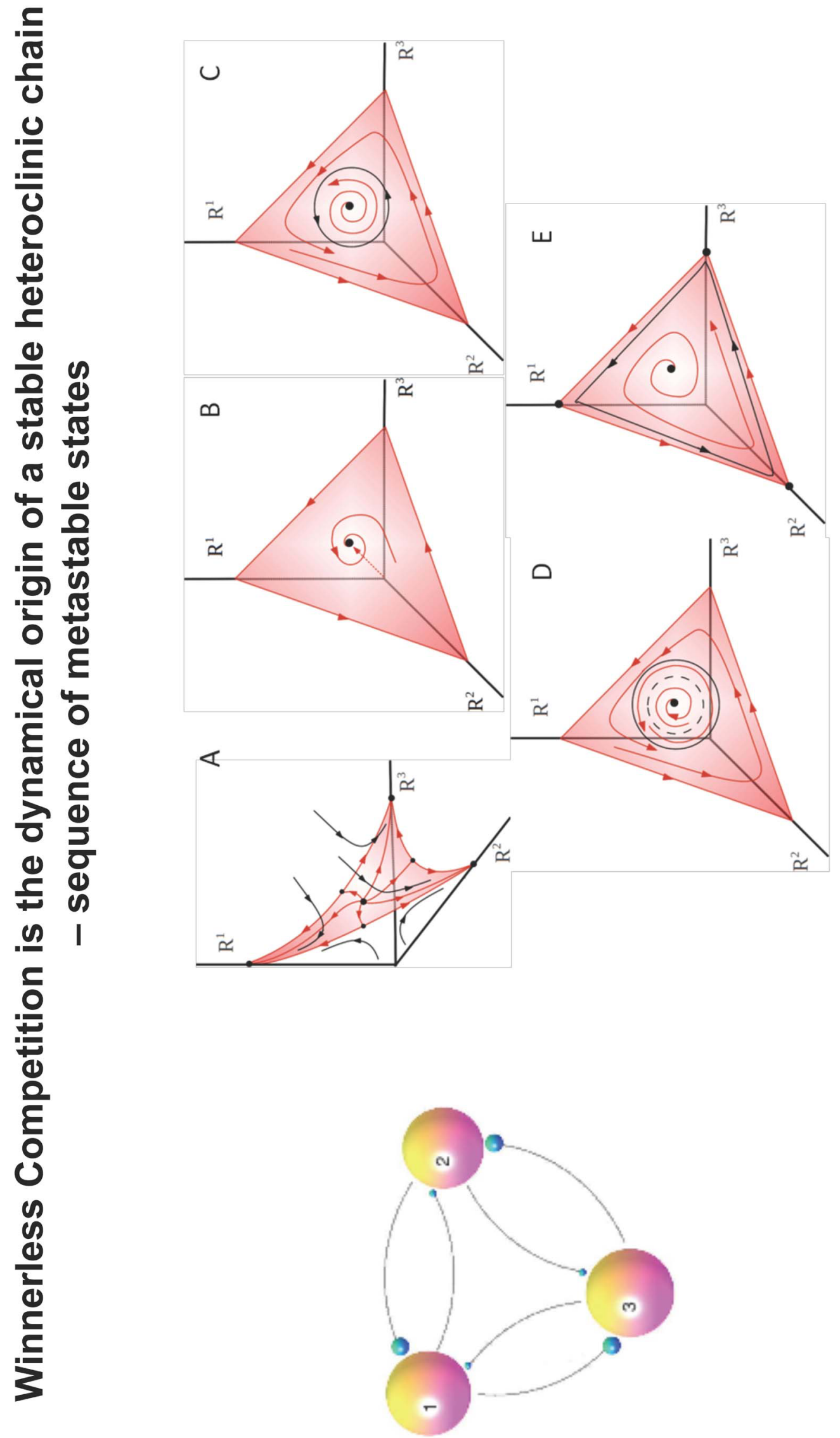

(C) М. Рабинович, П. Варона

Изв. вузов «ПНД», т. 25, № 3, 2017 

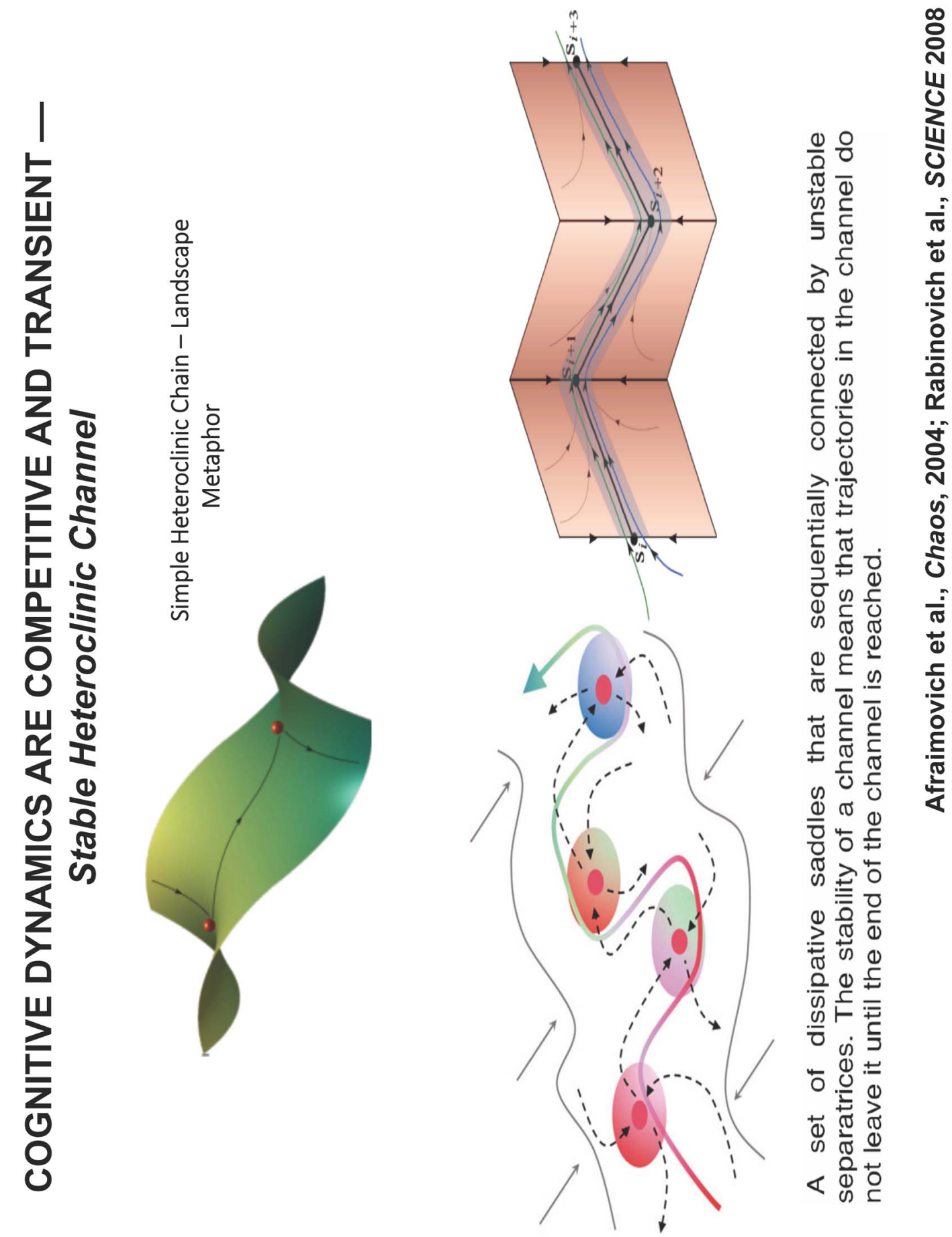

(C) М. Рабинович, П. Варона 


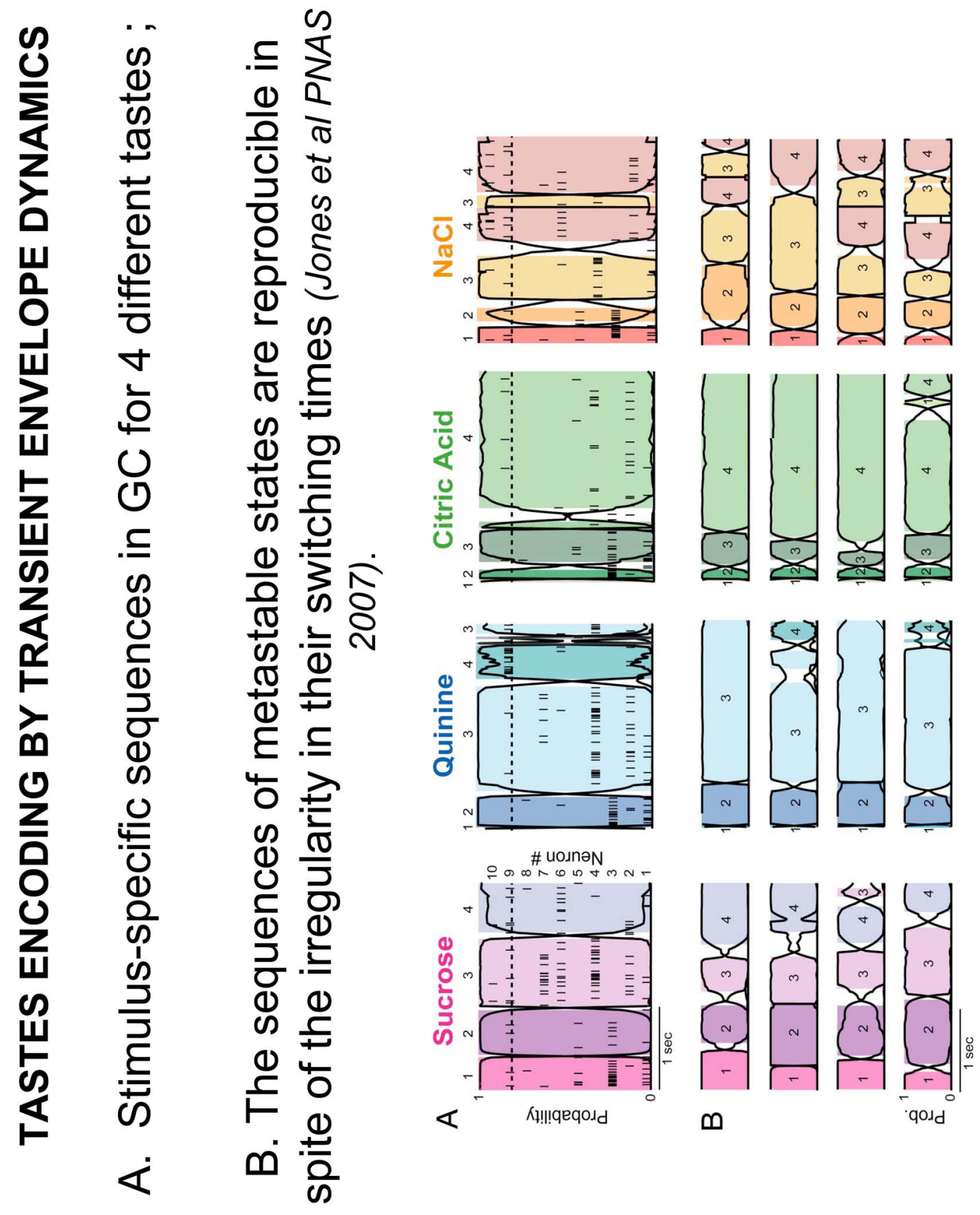




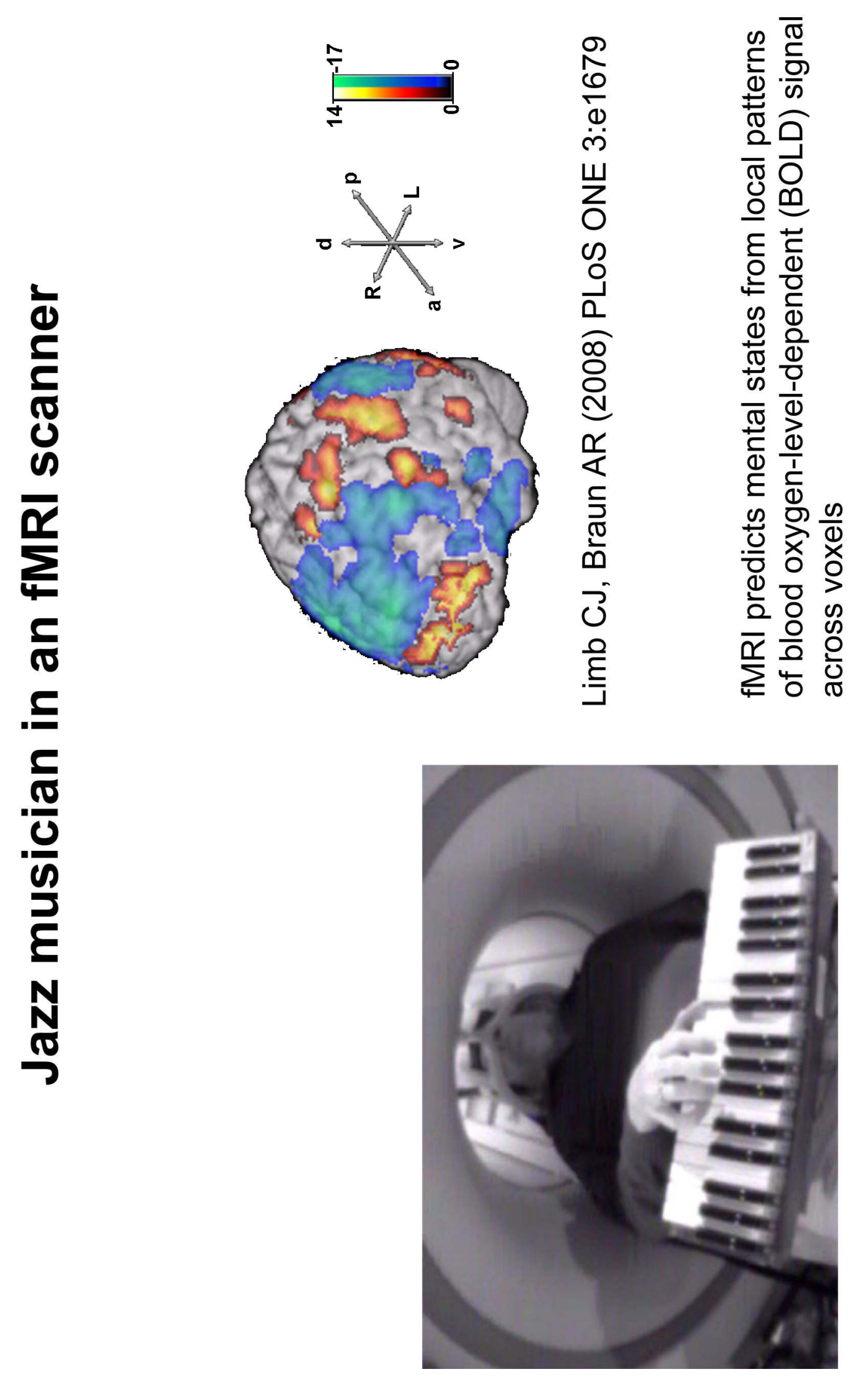

(c) М. Рабинович, П. Варона Изв. вузов «ПНД», т. 25, № 3, 2017 


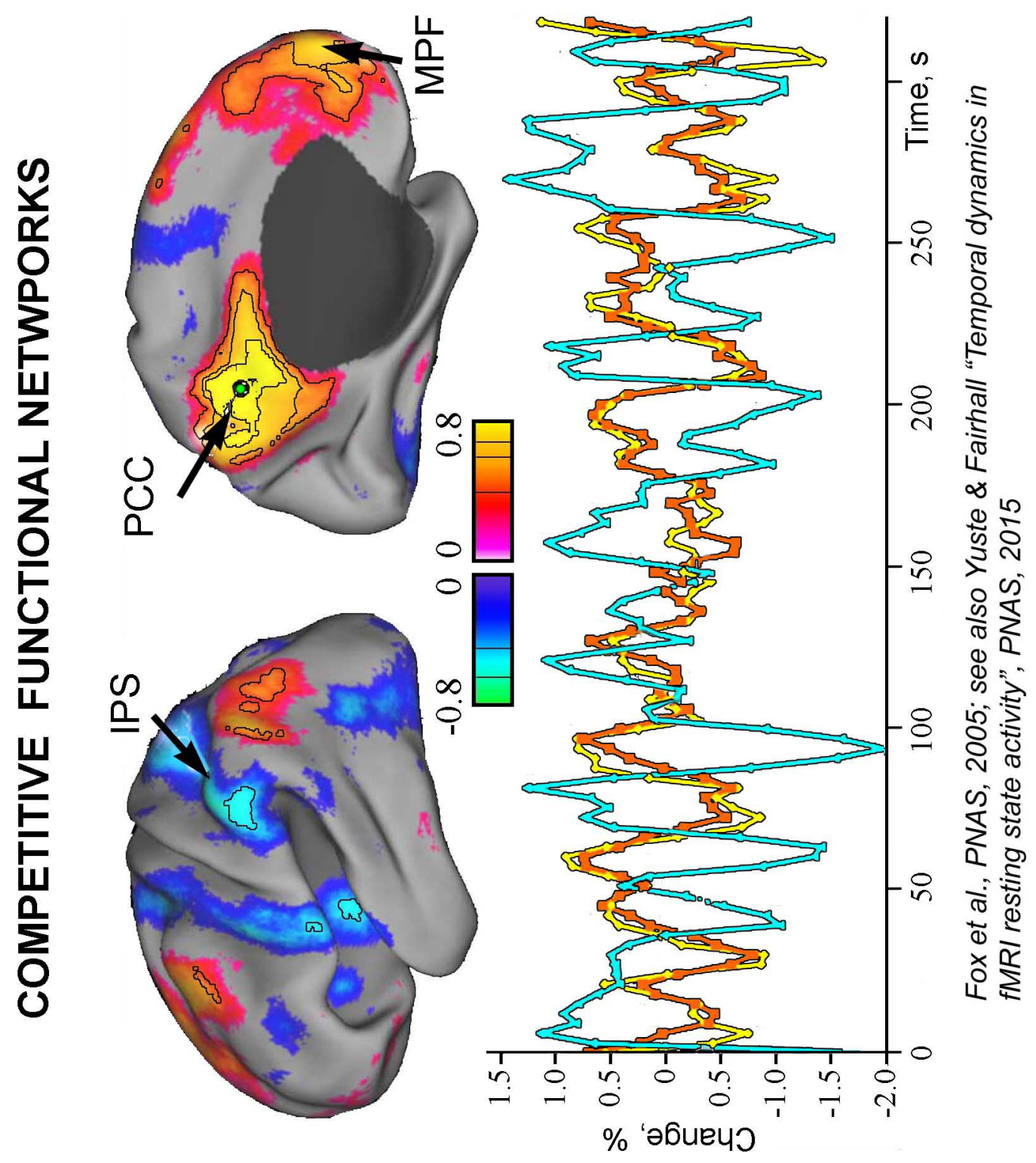

(C) М. Рабинович, П. Варона

Изв. вузов «ПНД», т. 25, № 3, 2017 


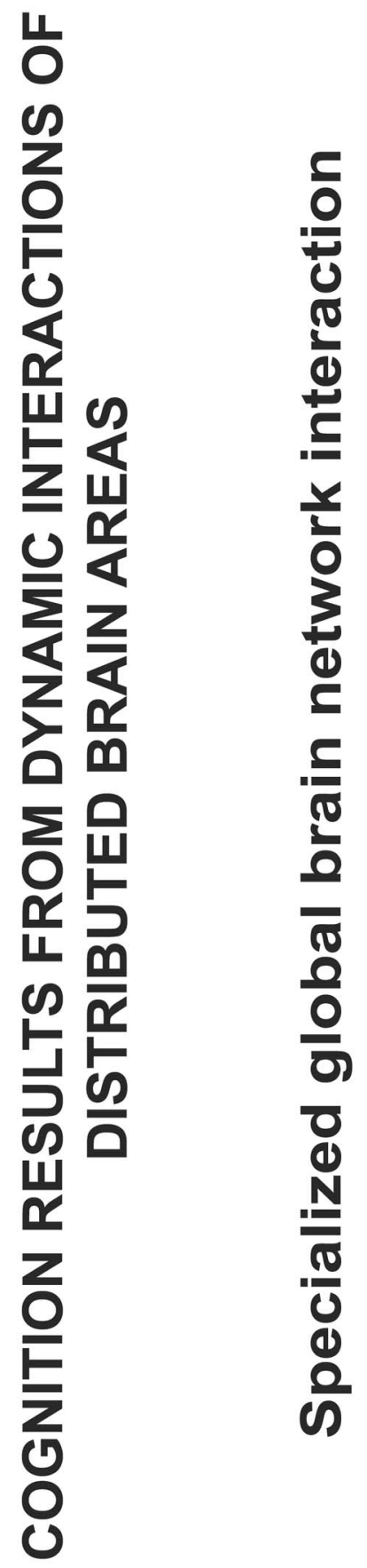

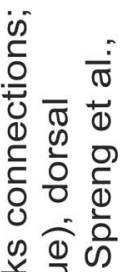

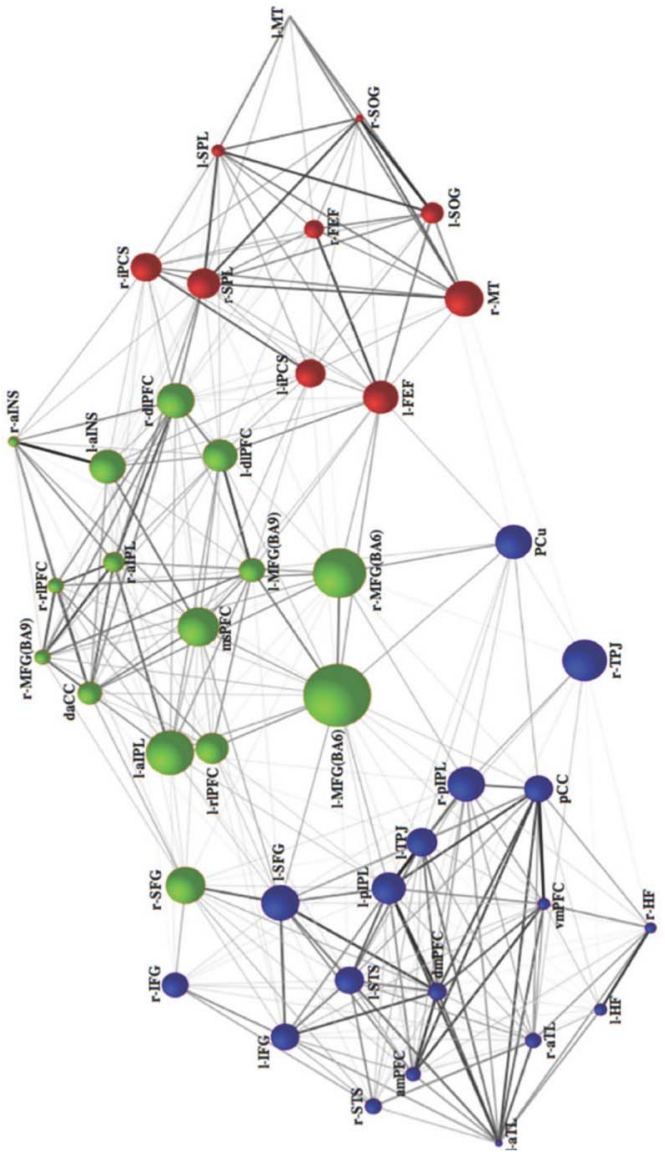

흐웡

要

ॠ

오웡ㅇํㅇ

ㅇํㅇㅎํ

ᄃ $\frac{1}{\mathrm{c}}$

응

ฮ

응

กั ธิ

立高这

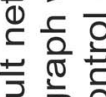

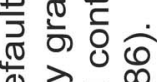

造起 $\frac{0}{\pi}$

(1) 岂

1

웡 它 인

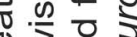

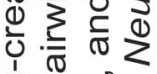
을 읗

ह

등 둥

능

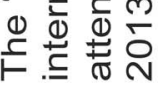

(C) М. Рабинович, П. Варона 


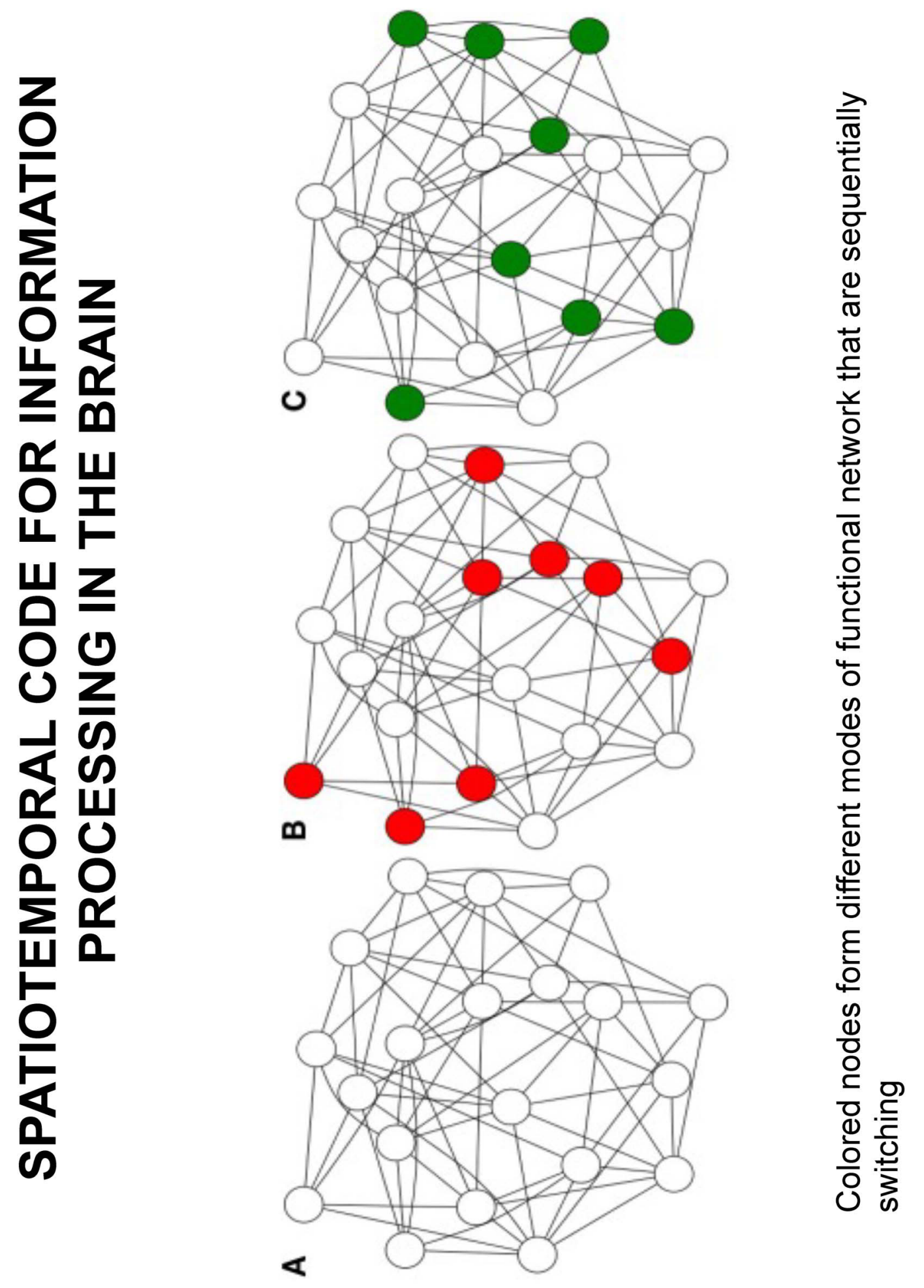

(C) М. Рабинович, П. Варона

Изв. вузов «ПНД», т. 25, № 3, 2017 


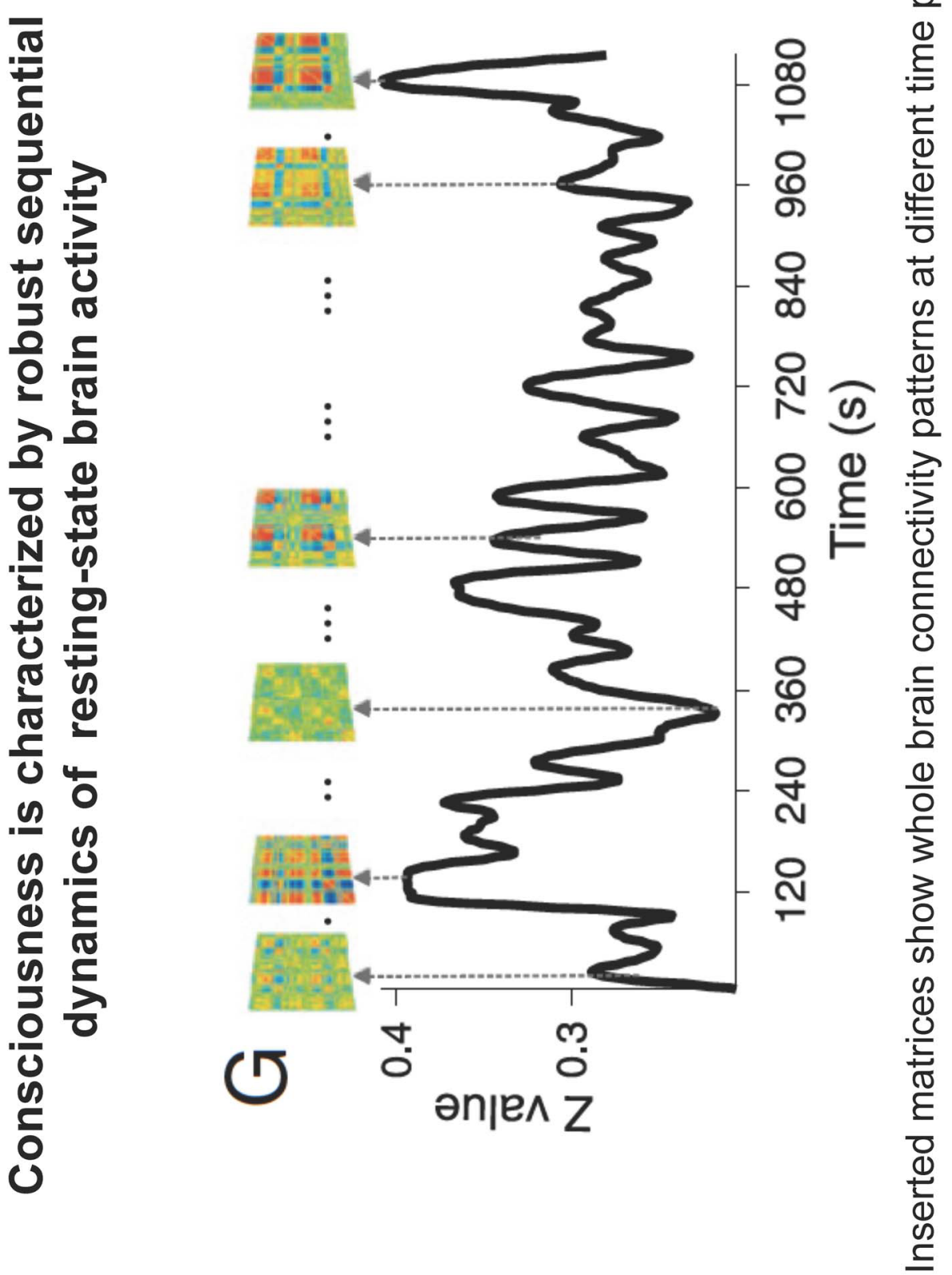

(C) М. Рабинович, П. Варона 


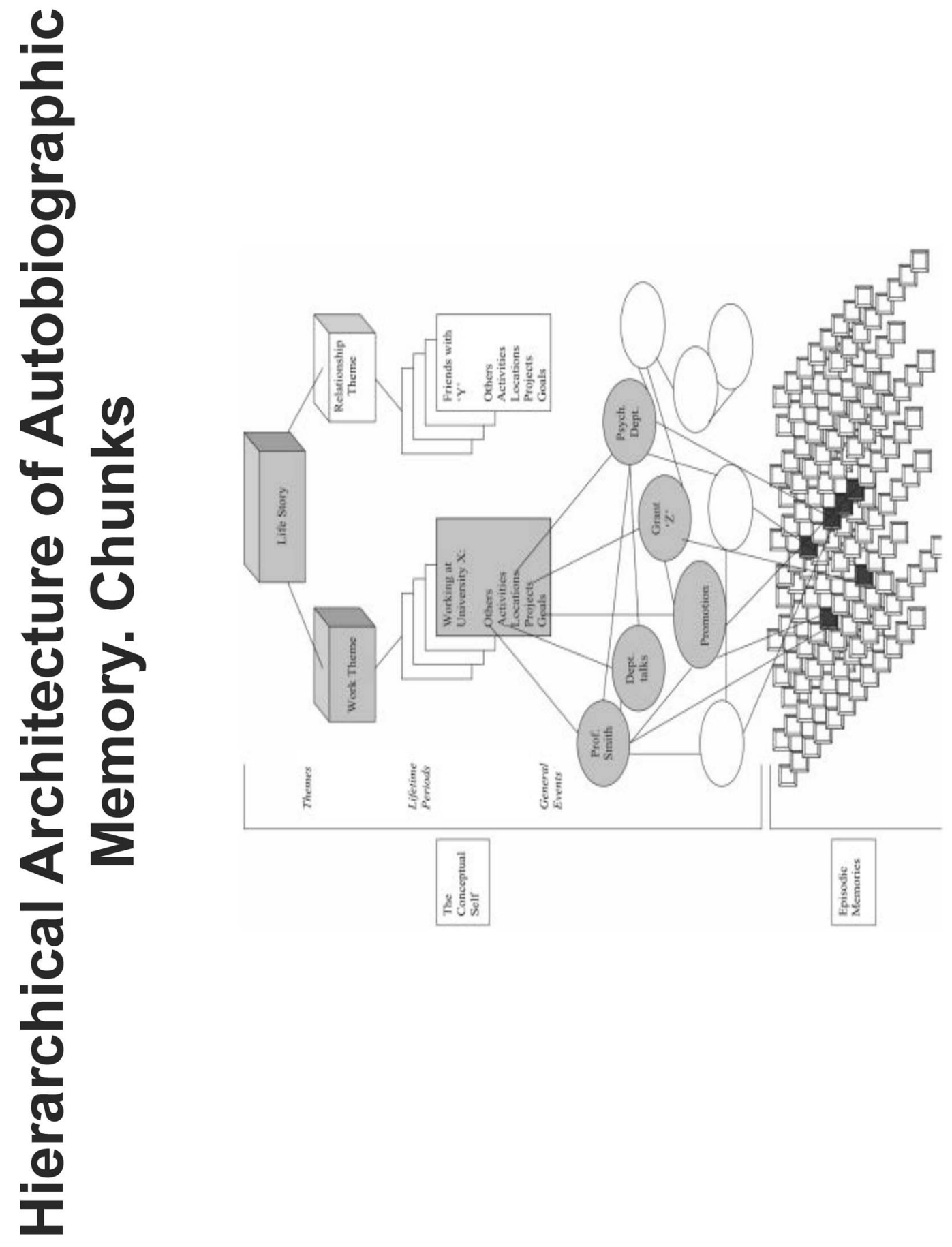

(C) М. Рабинович, П. Варона

Изв. вузов «ПНД», т. 25, № 3, 2017 

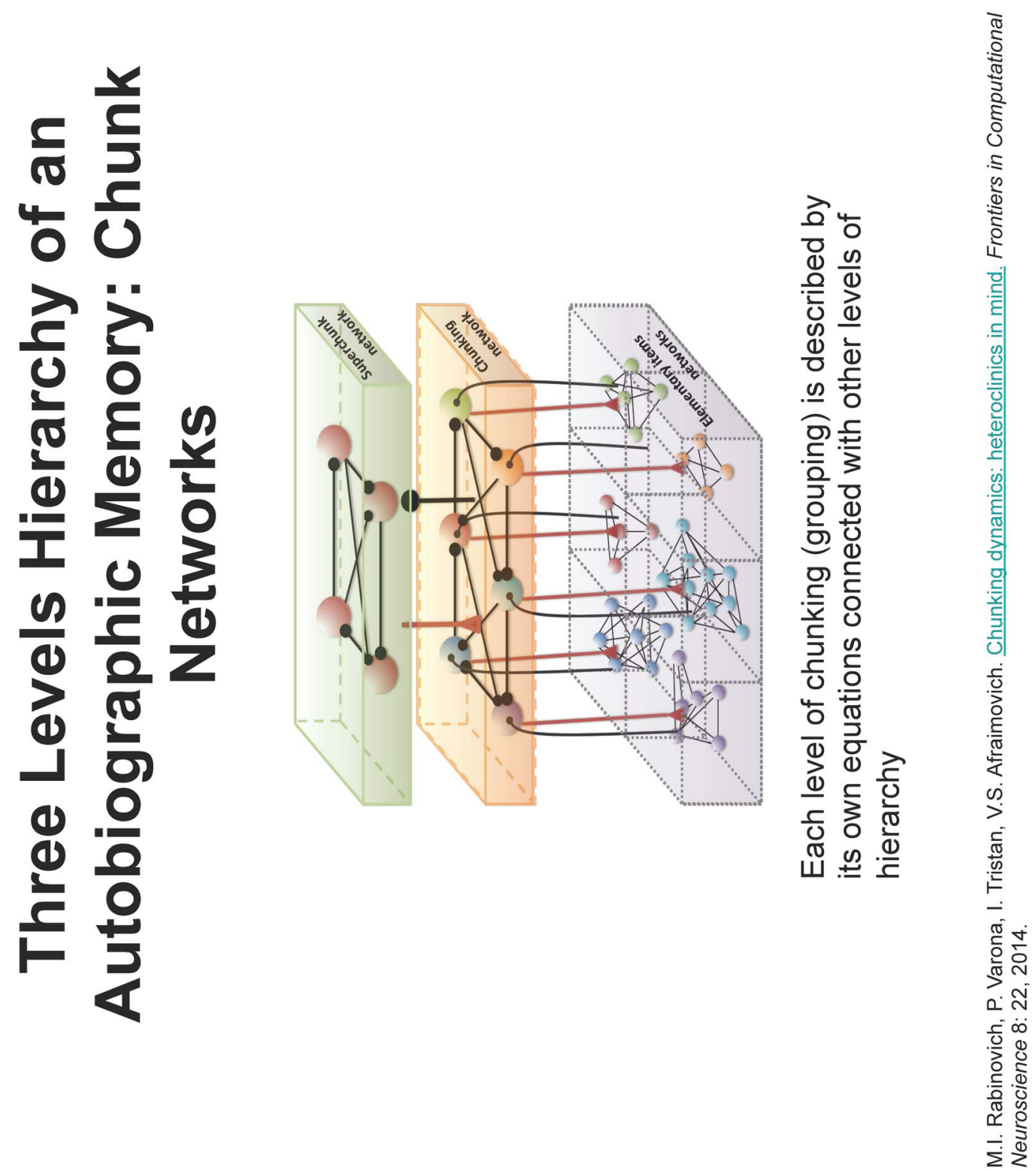

(C) М. Рабинович, П. Варона 


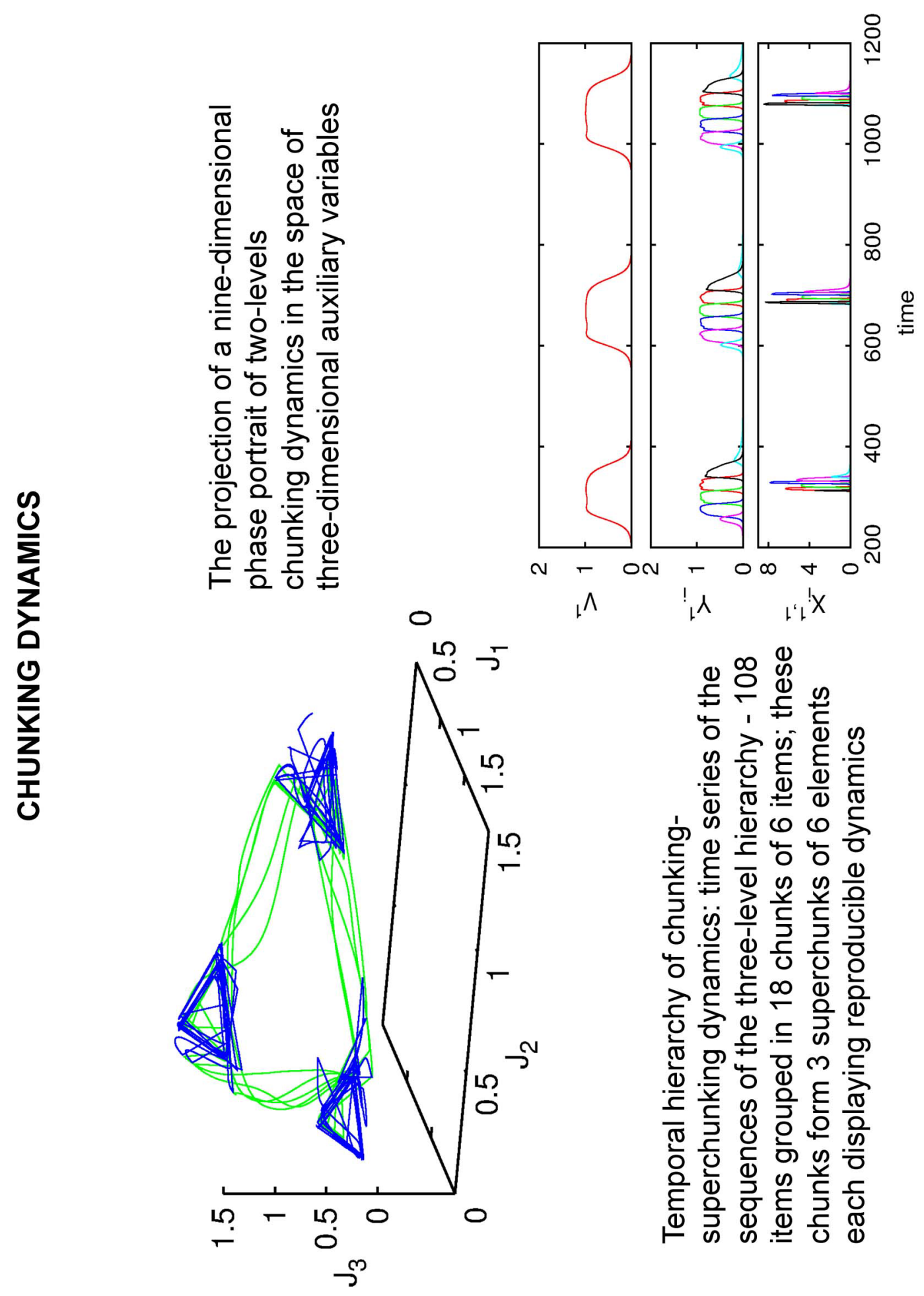

(C) М. Рабинович, П. Варона

Изв. вузов «ПНД», т. 25, № 3, 2017 


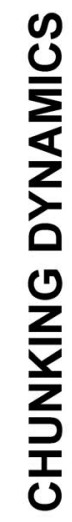
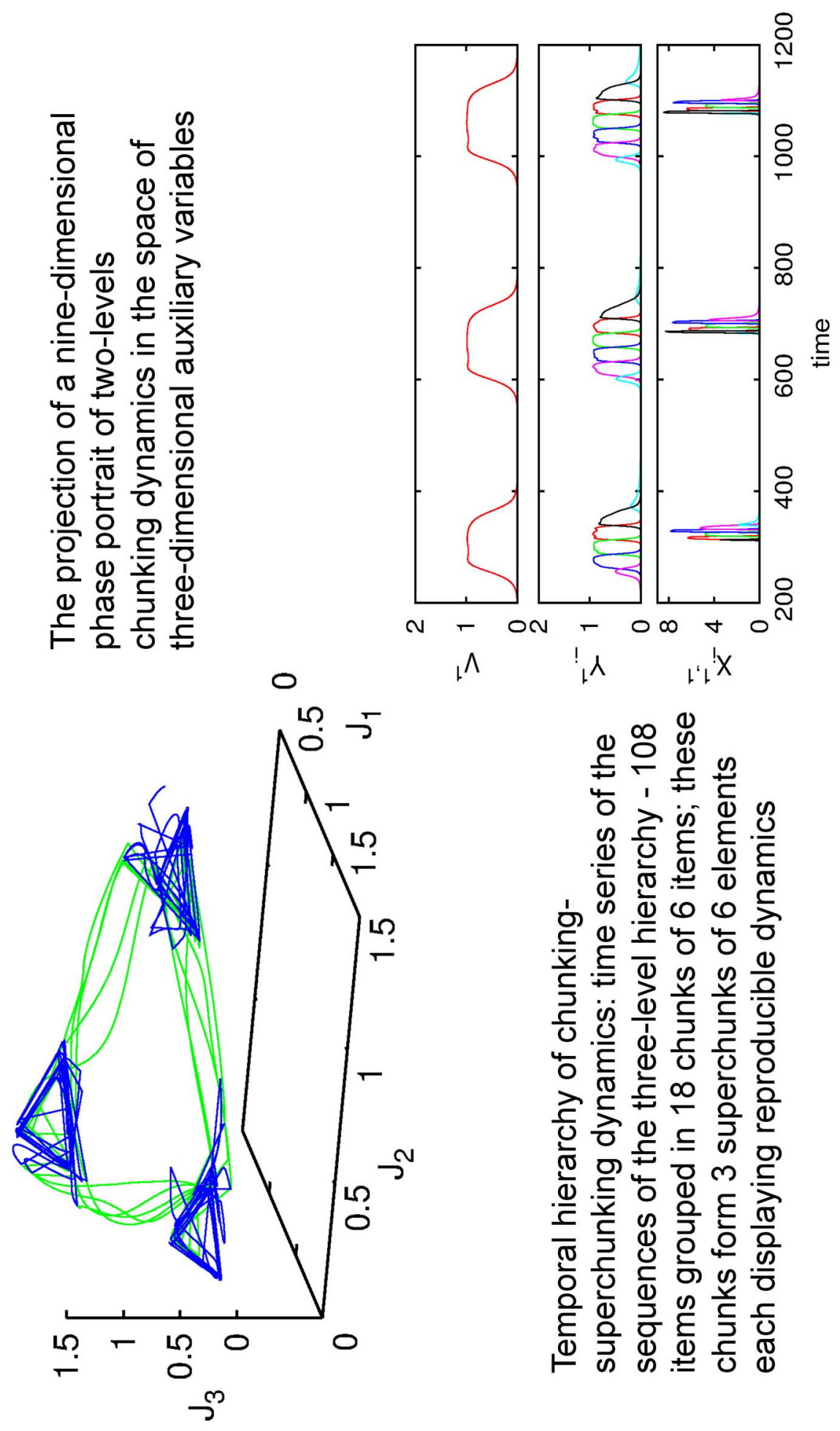

(1)

$\risingdotseq \stackrel{\oiiint}{\ddagger}$

क त्र

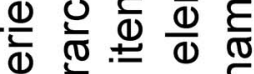

宁

ㄷㅀ

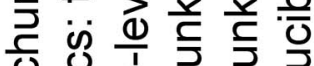

U. 일 ⿺辶⿱

0 兄 $\infty$ 造

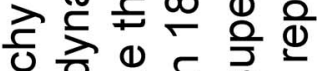

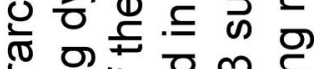

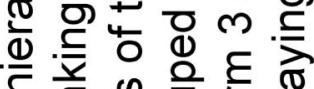

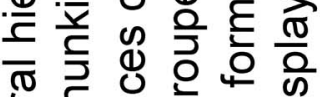

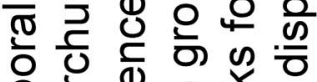

을 岂 ผ 兵

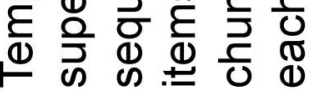

(C) М. Рабинович, П. Варона 


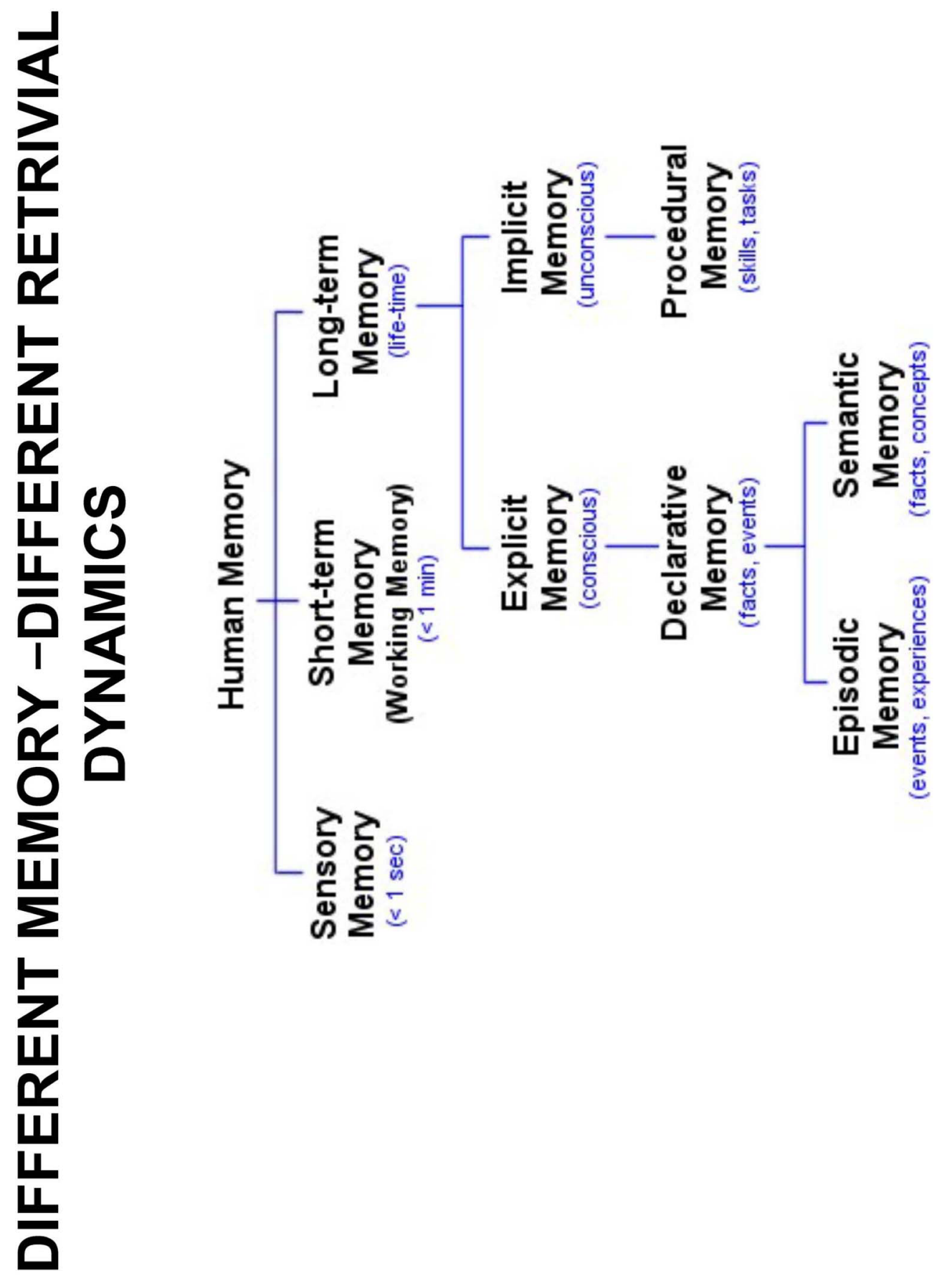



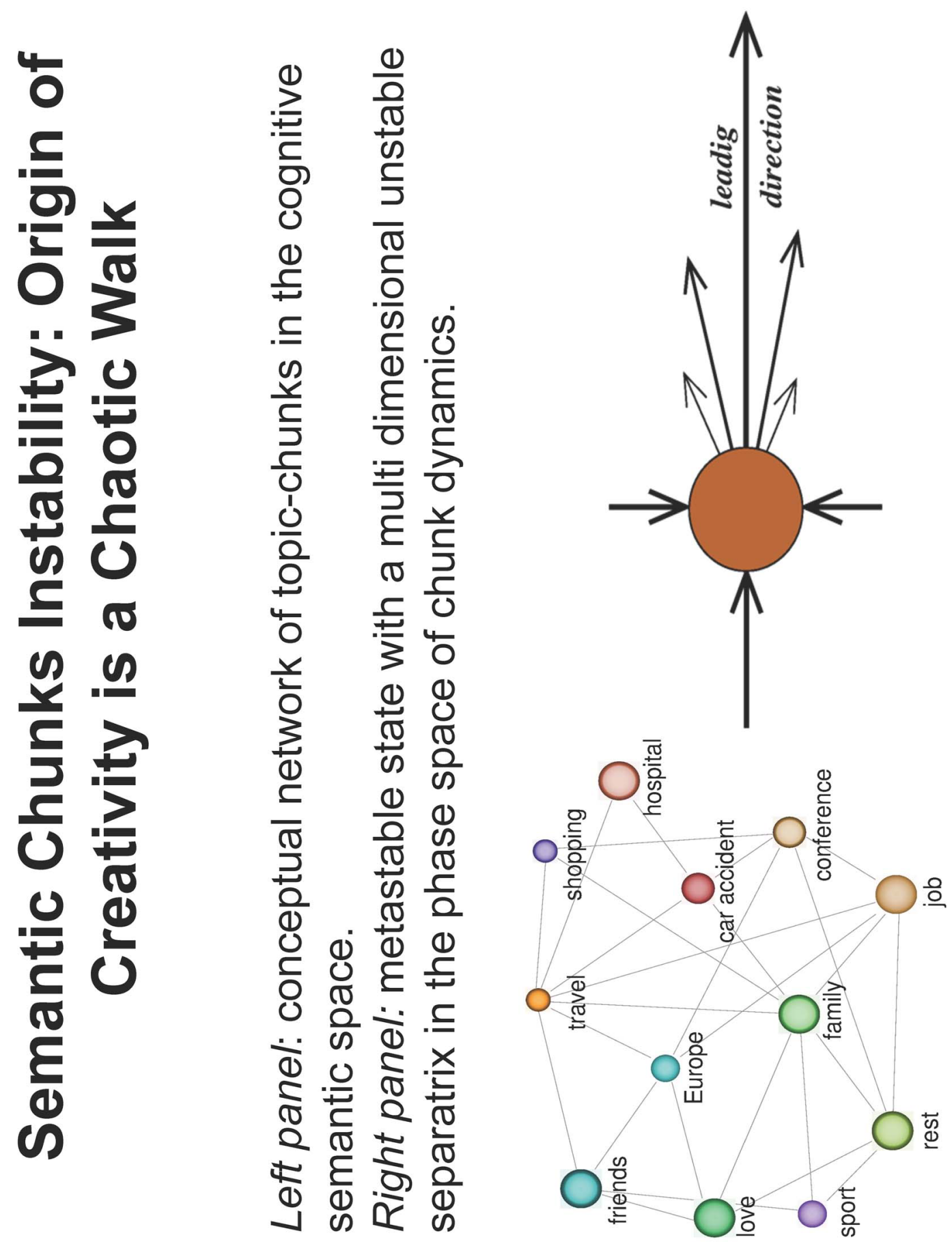

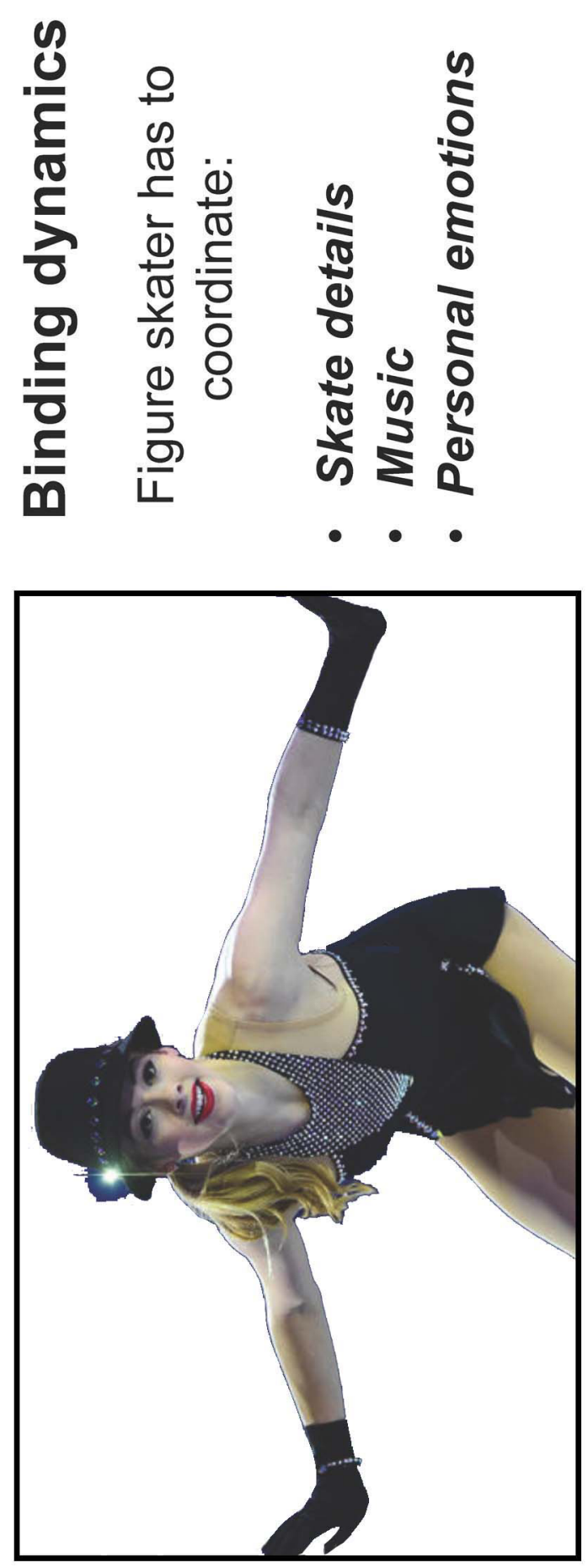

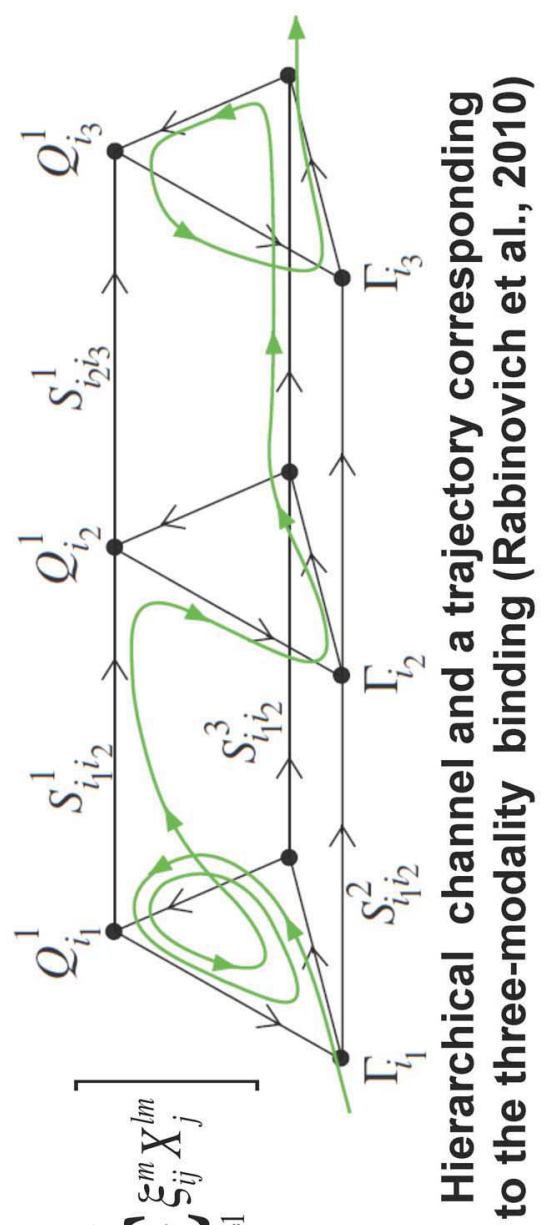

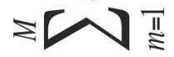
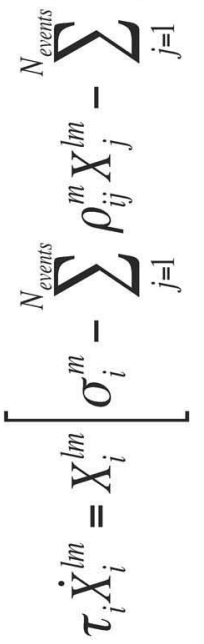


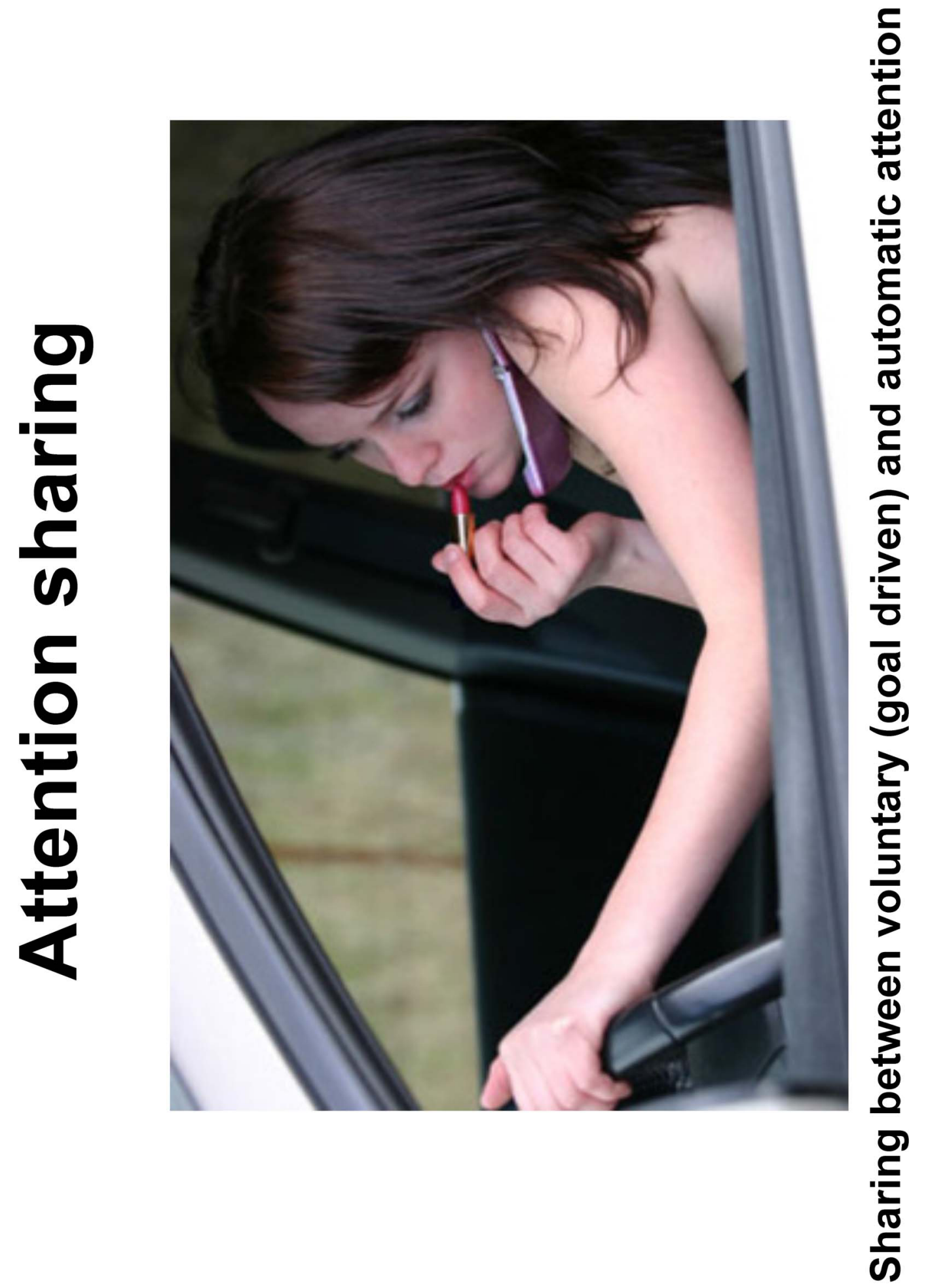

(C) М. Рабинович, П. Варона 


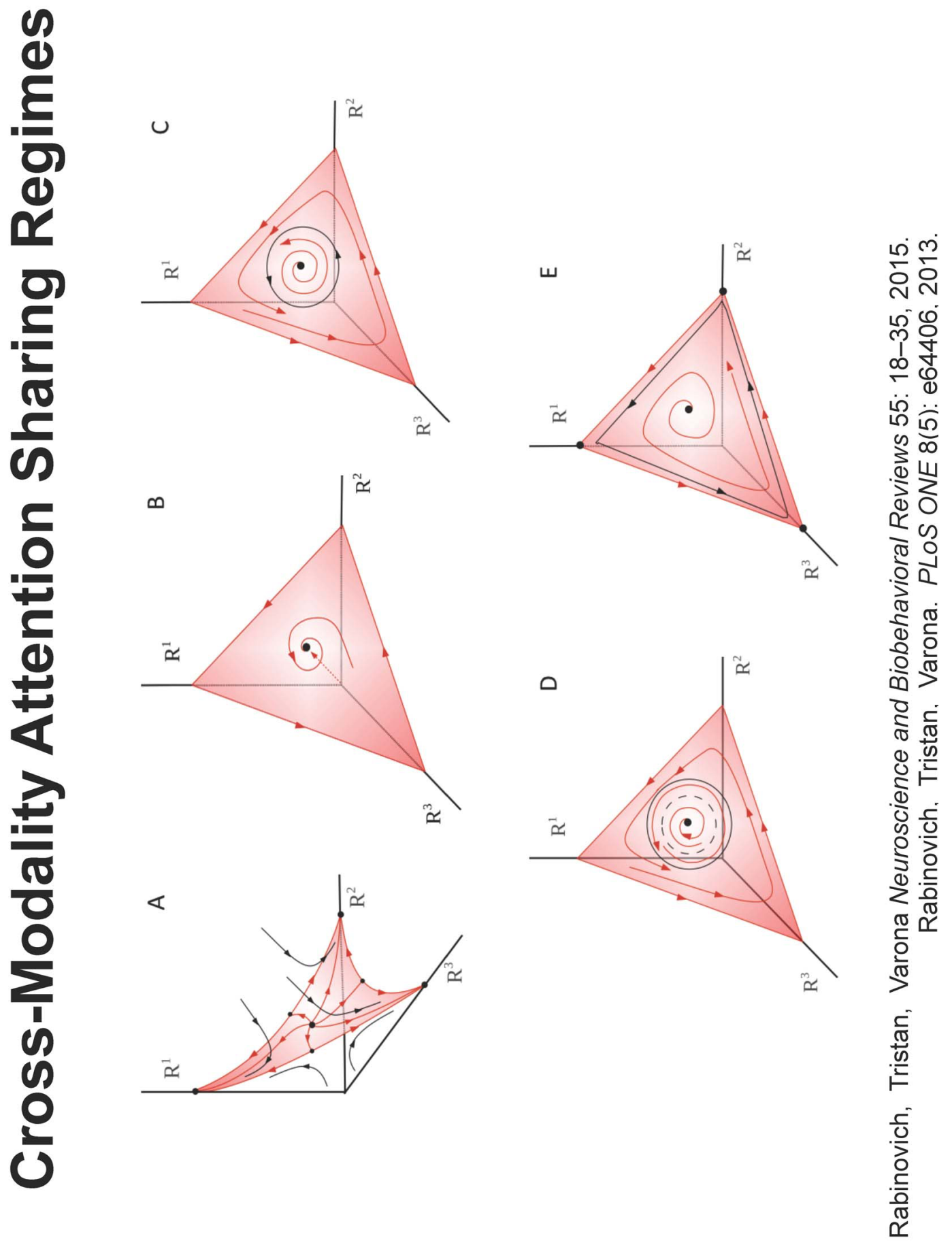

(C) М. Рабинович, П. Варона

Изв. вузов «ПНД», т. 25, № 3, 2017 

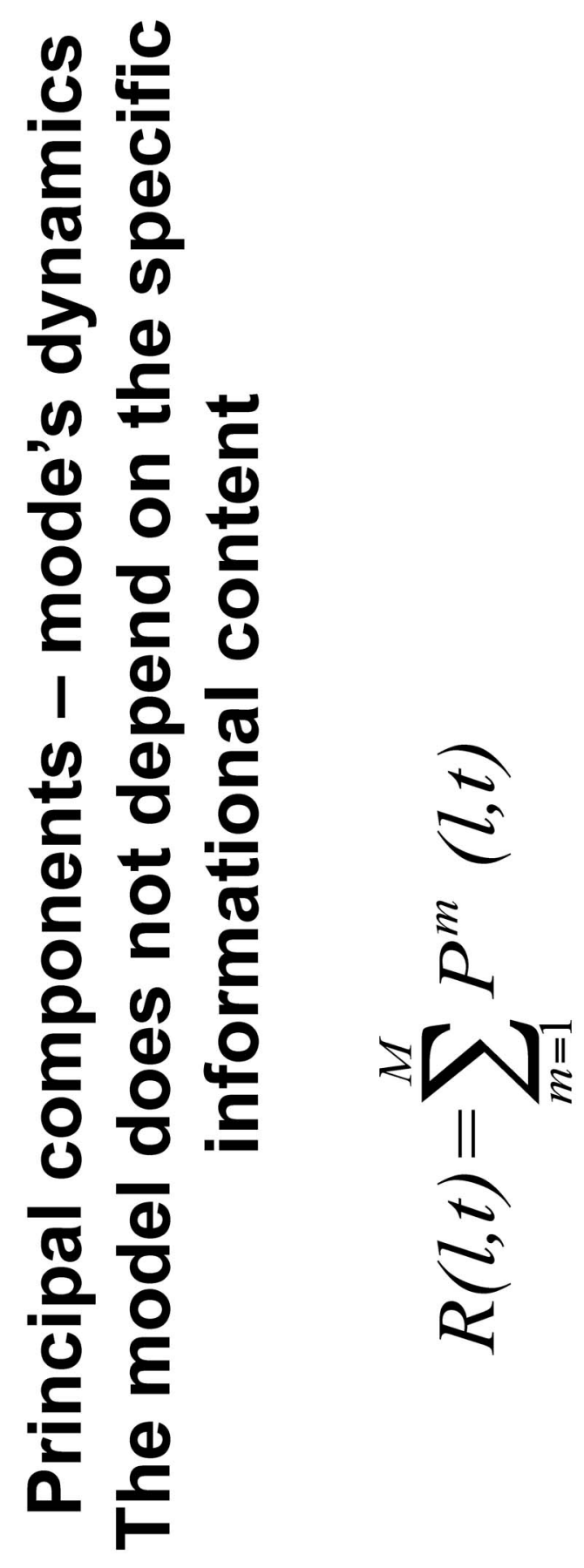
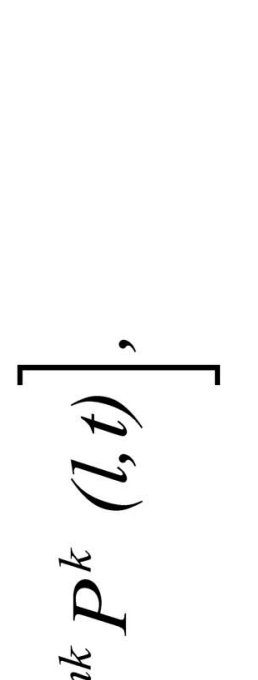

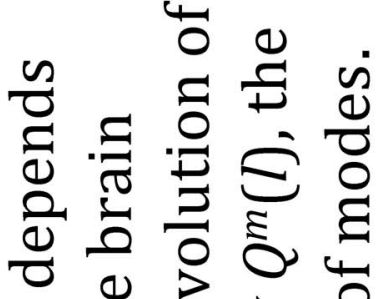
它焉光 ๘

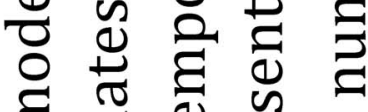
E

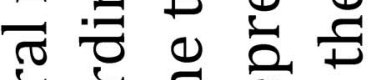
○ 0 든 릉

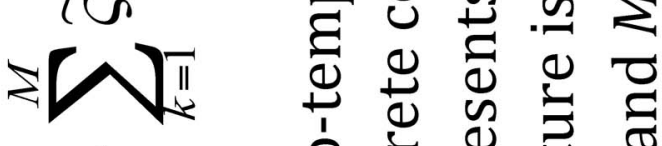
๖

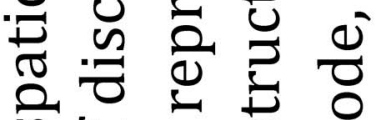
ì

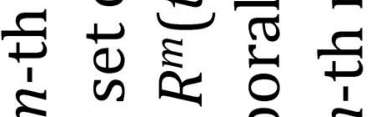
(1)

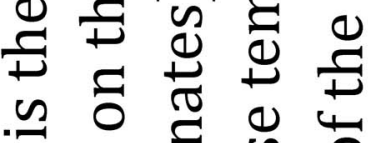

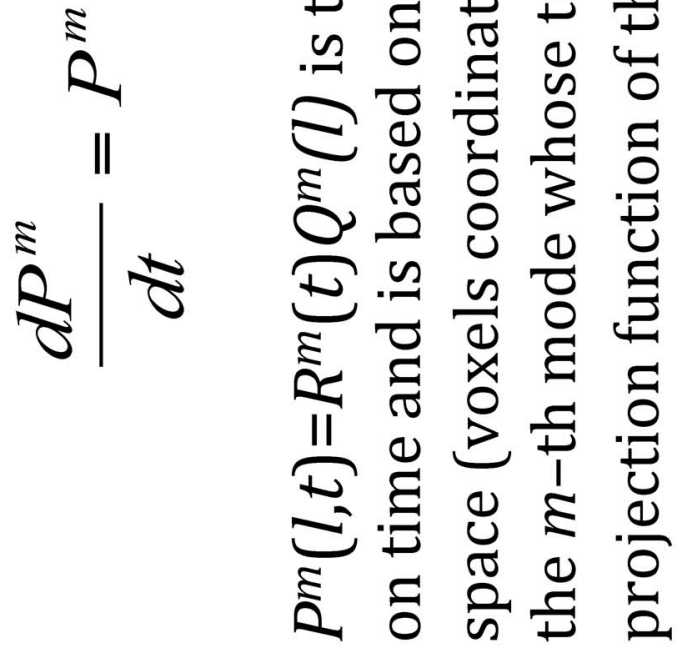

(c) М. Рабинович, П. Варона Изв. вузов «ПНД», т. 25, № 3, 2017 


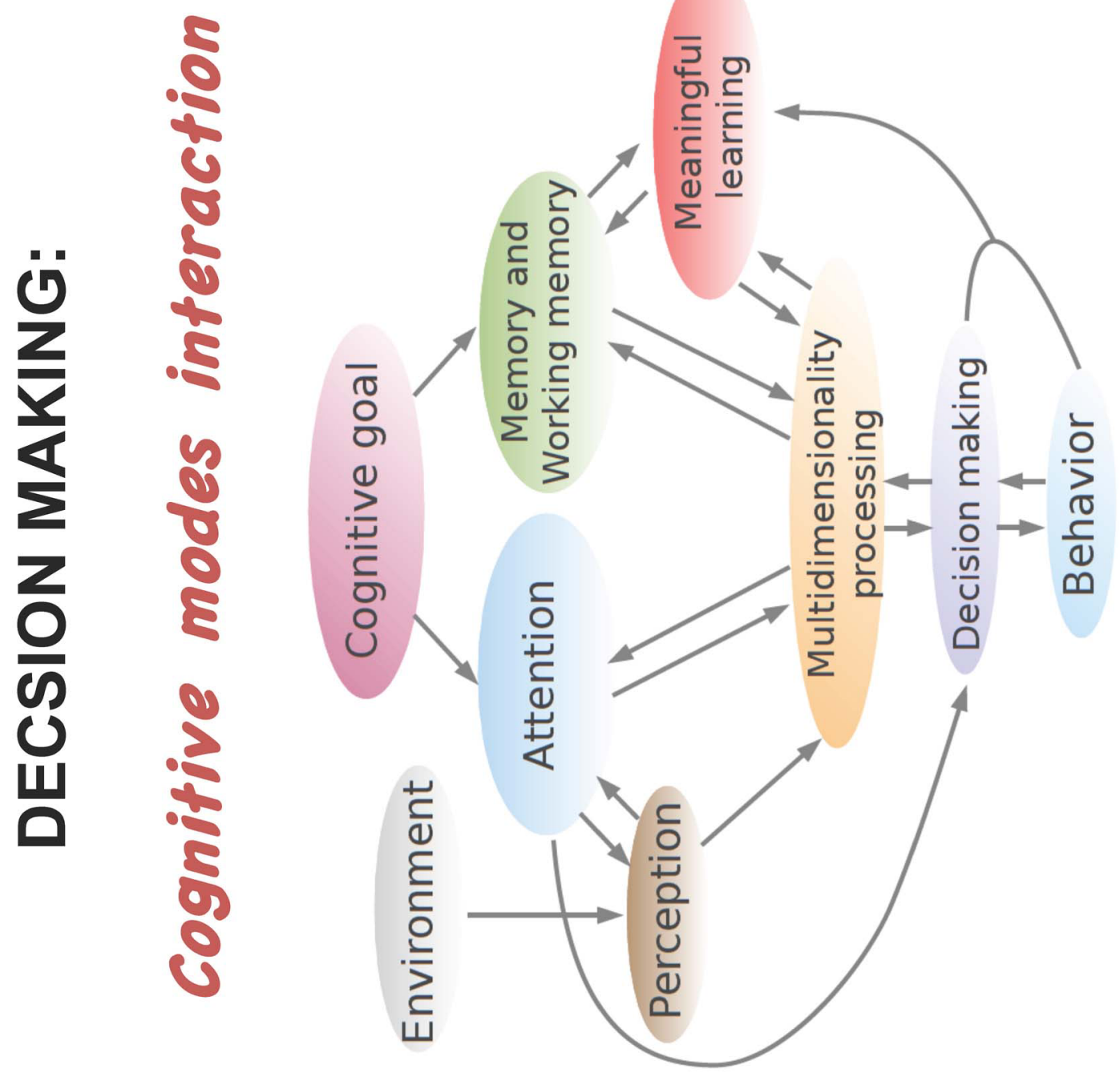



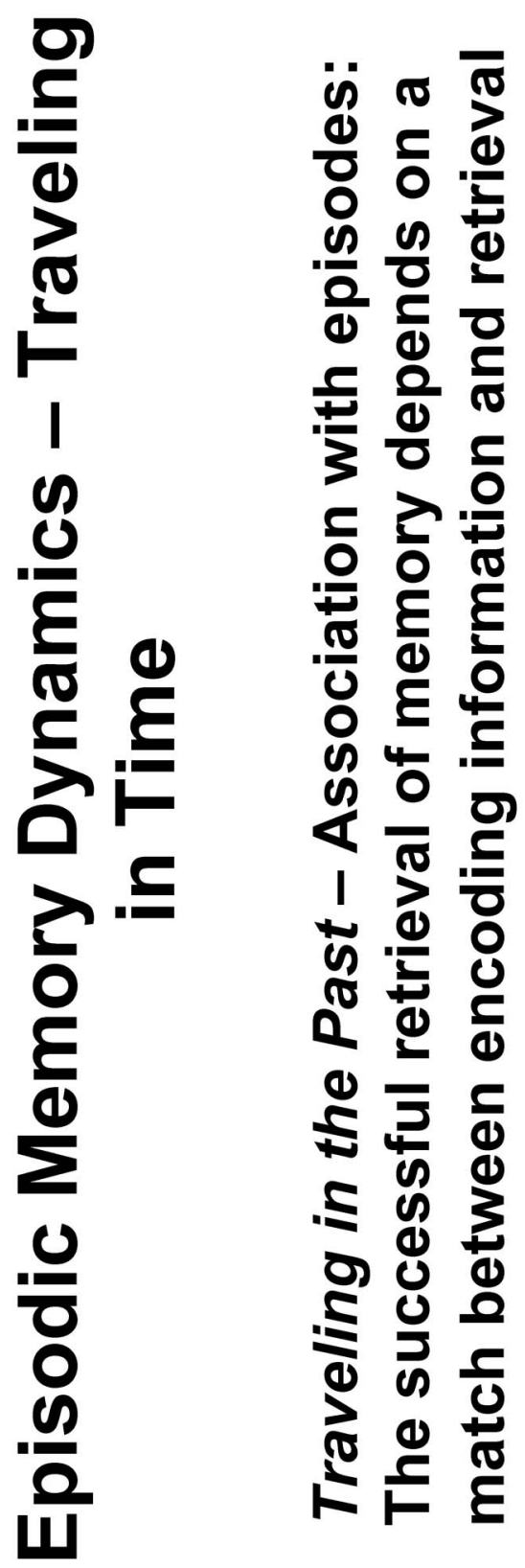

퐁

के

๑

이

옹

응 응

도 응 은

읃

드.

๑

을

क्ष

인 읒

논

은

\& 4 .

क 0 잉

1 응

는

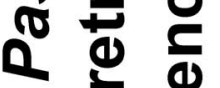

느 흐

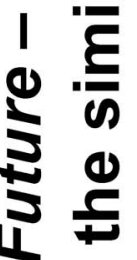

ఏ

응

$\$$

$\leqslant \stackrel{\Phi}{ \pm}$

오응

$\leqslant 8$

Ð

它是

음 응 은

들 응 응

음 인 중

ต 0

도 트

\% 0.

늘

- E

눈

(s)

ชิ

๑ ㅇํㅇ

$\leqslant 0$

오 동

돈

बे 0 in

ह 는

ఏ ఏ

है

50

I.

ธ

ฐ

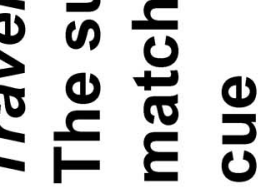

$\rightarrow 5$ 


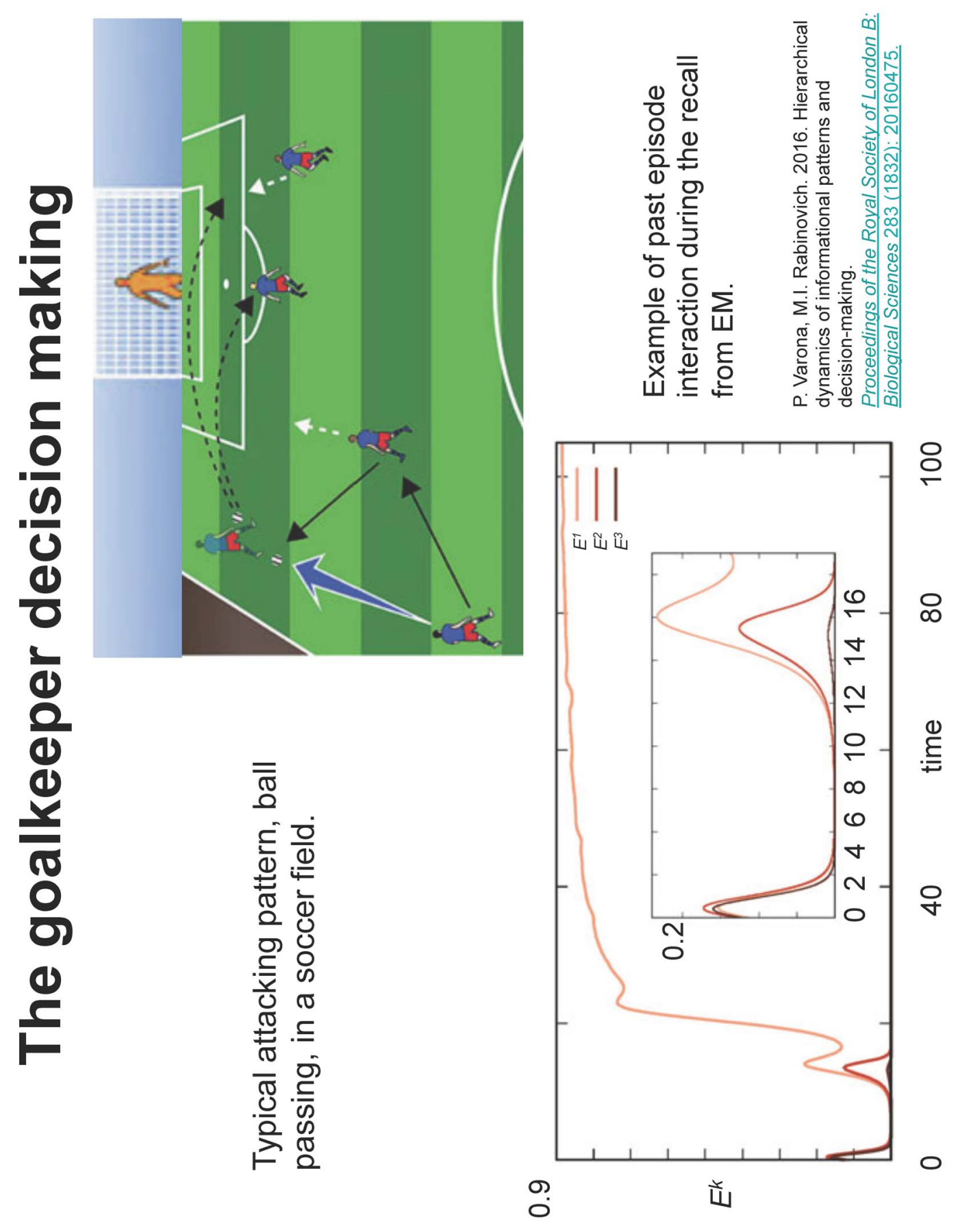

(C) М. Рабинович, П. Варона

Изв. вузов «ПНД», т. 25, № 3, 2017 


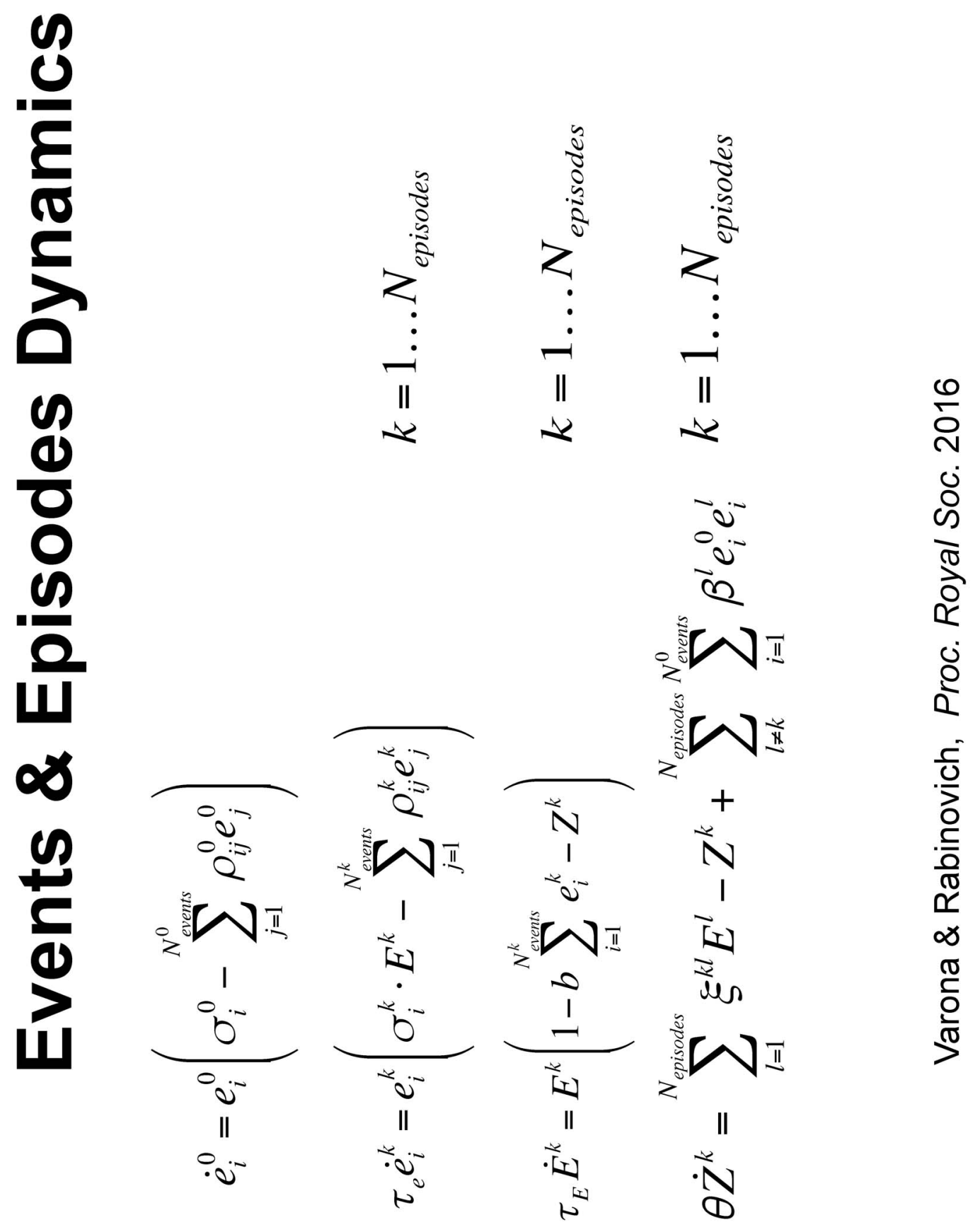

(C) М. Рабинович, П. Варона 


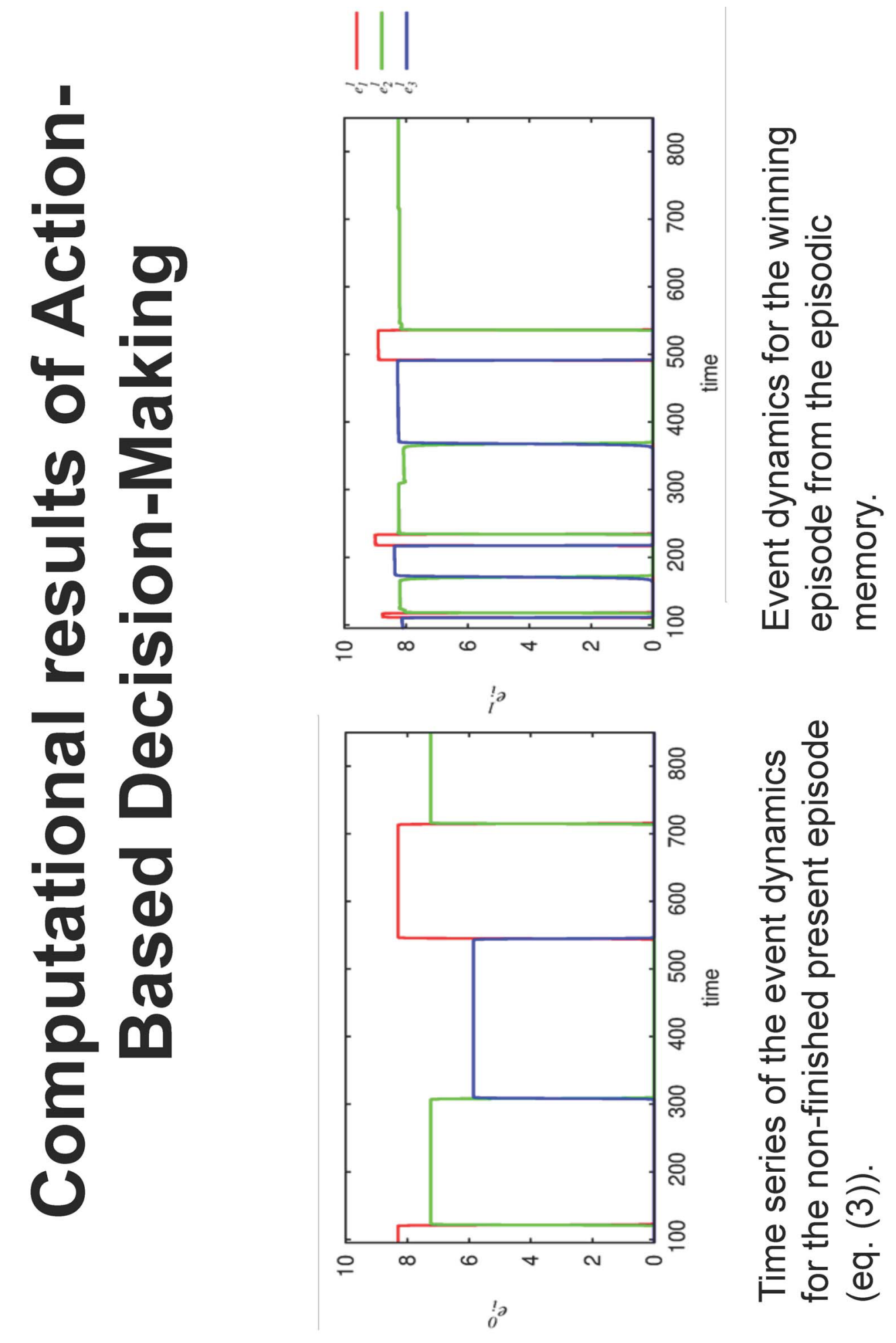

(C) М. Рабинович, П. Варона

Изв. вузов «ПНД», т. 25, № 3, 2017 


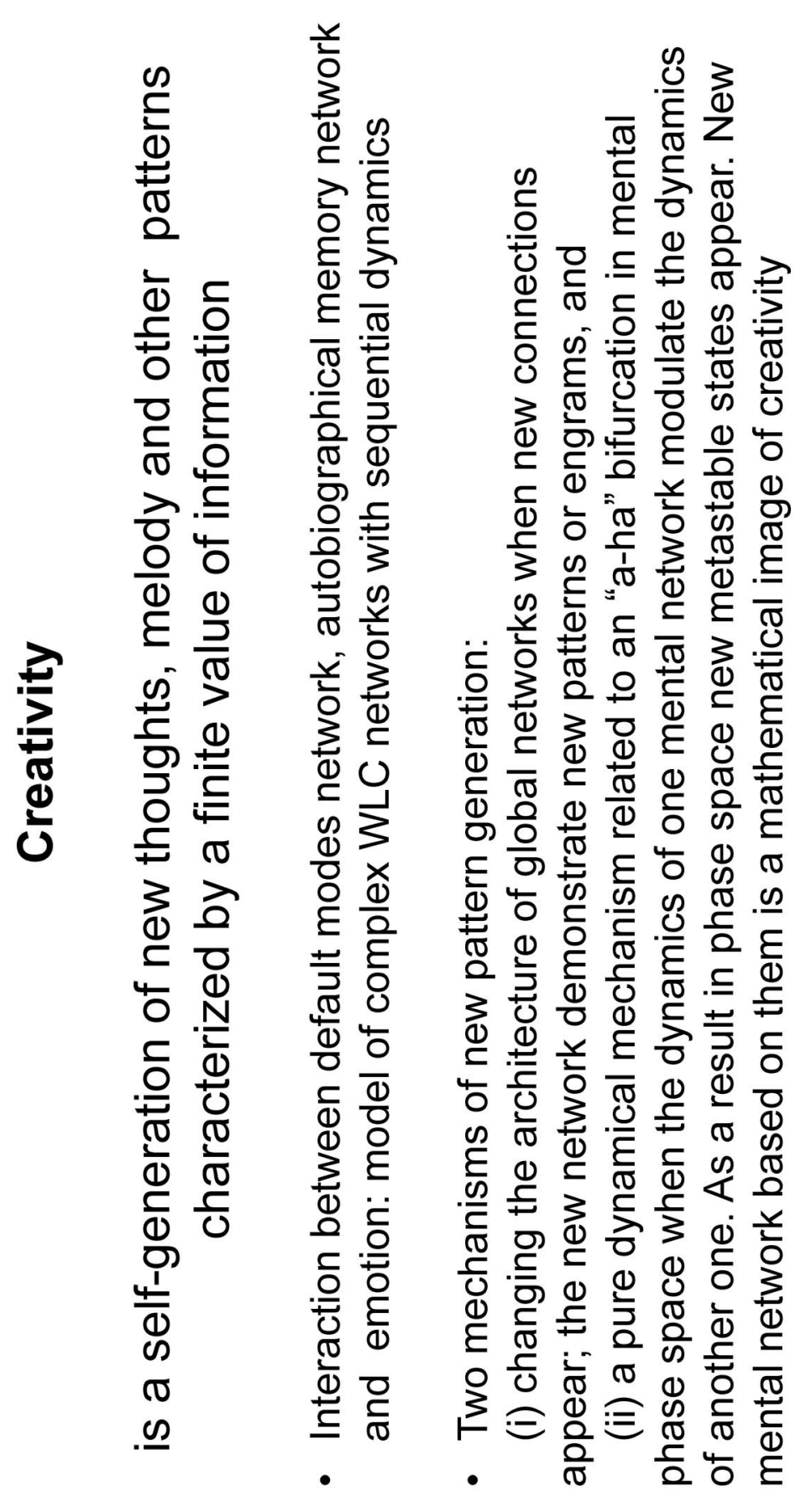




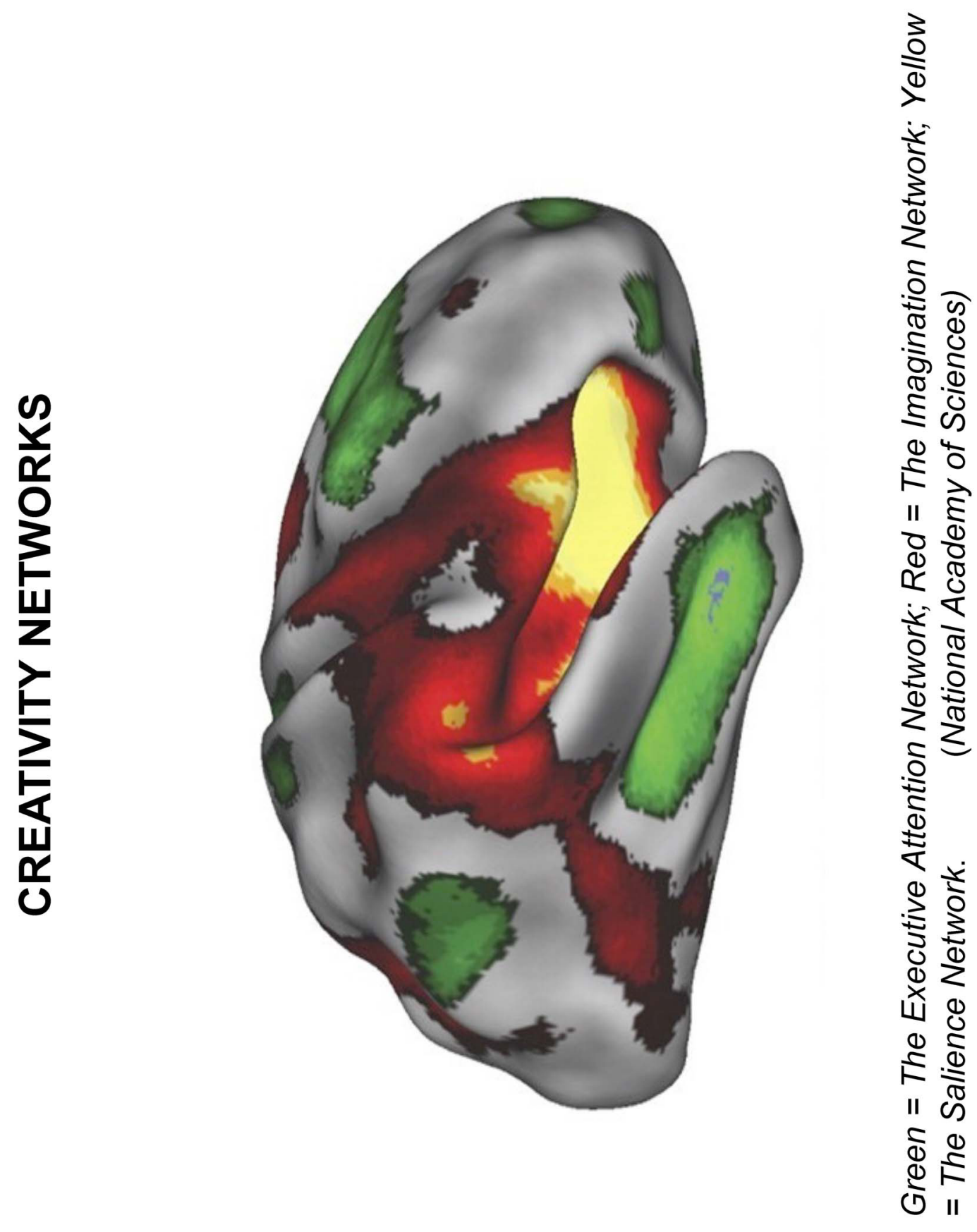



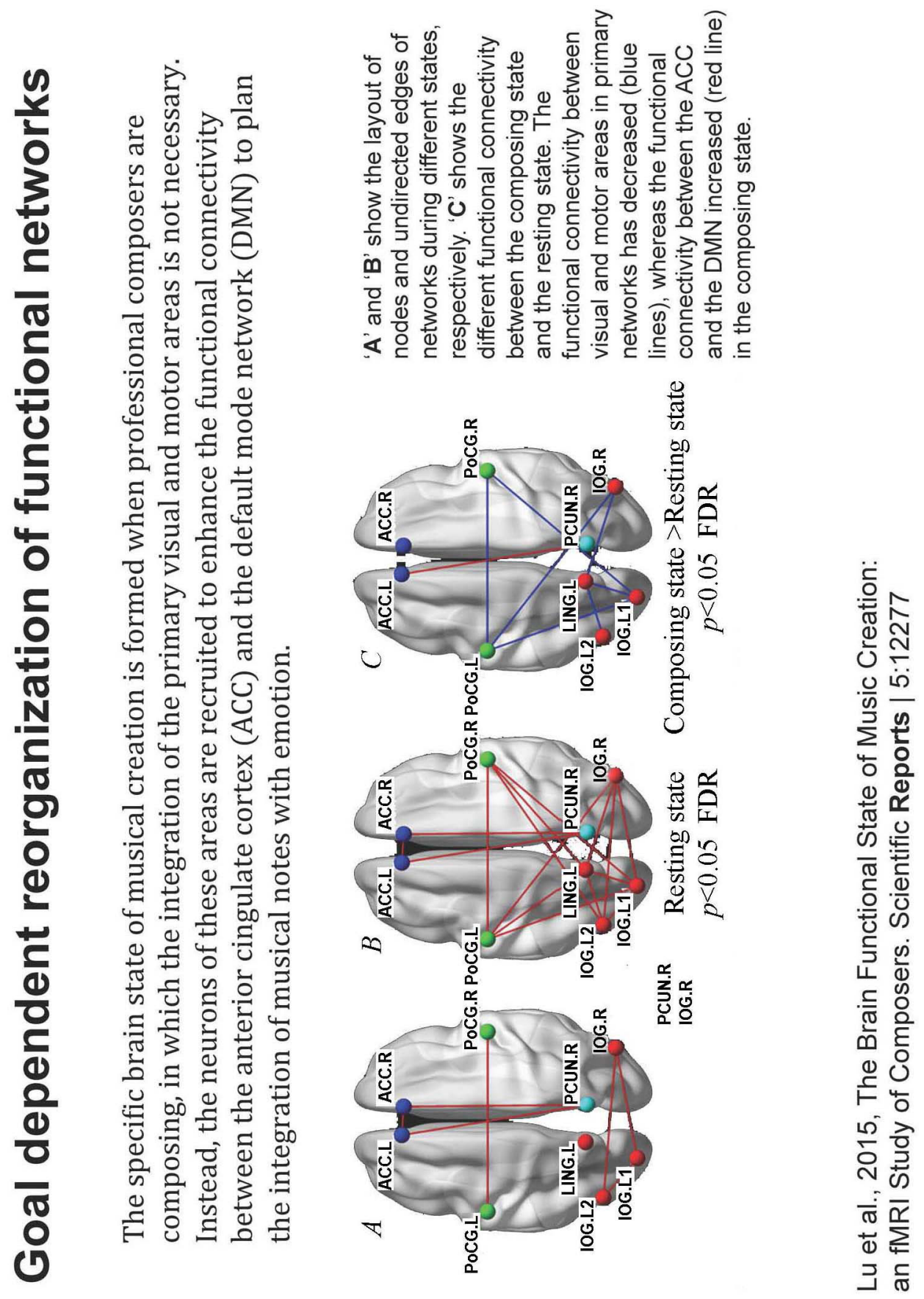

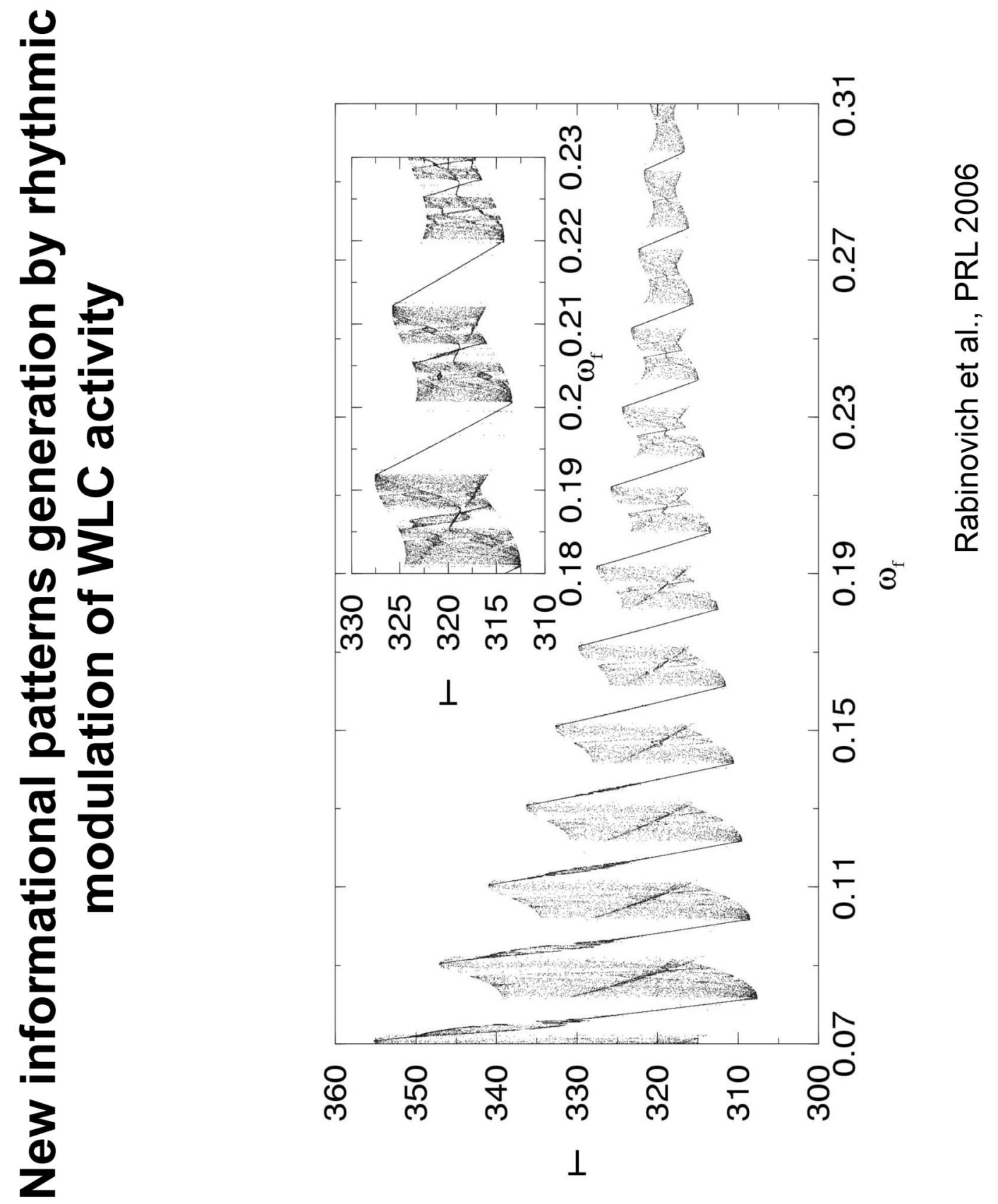

(C) М. Рабинович, П. Варона

Изв. вузов «ПНД», т. 25, № 3, 2017 

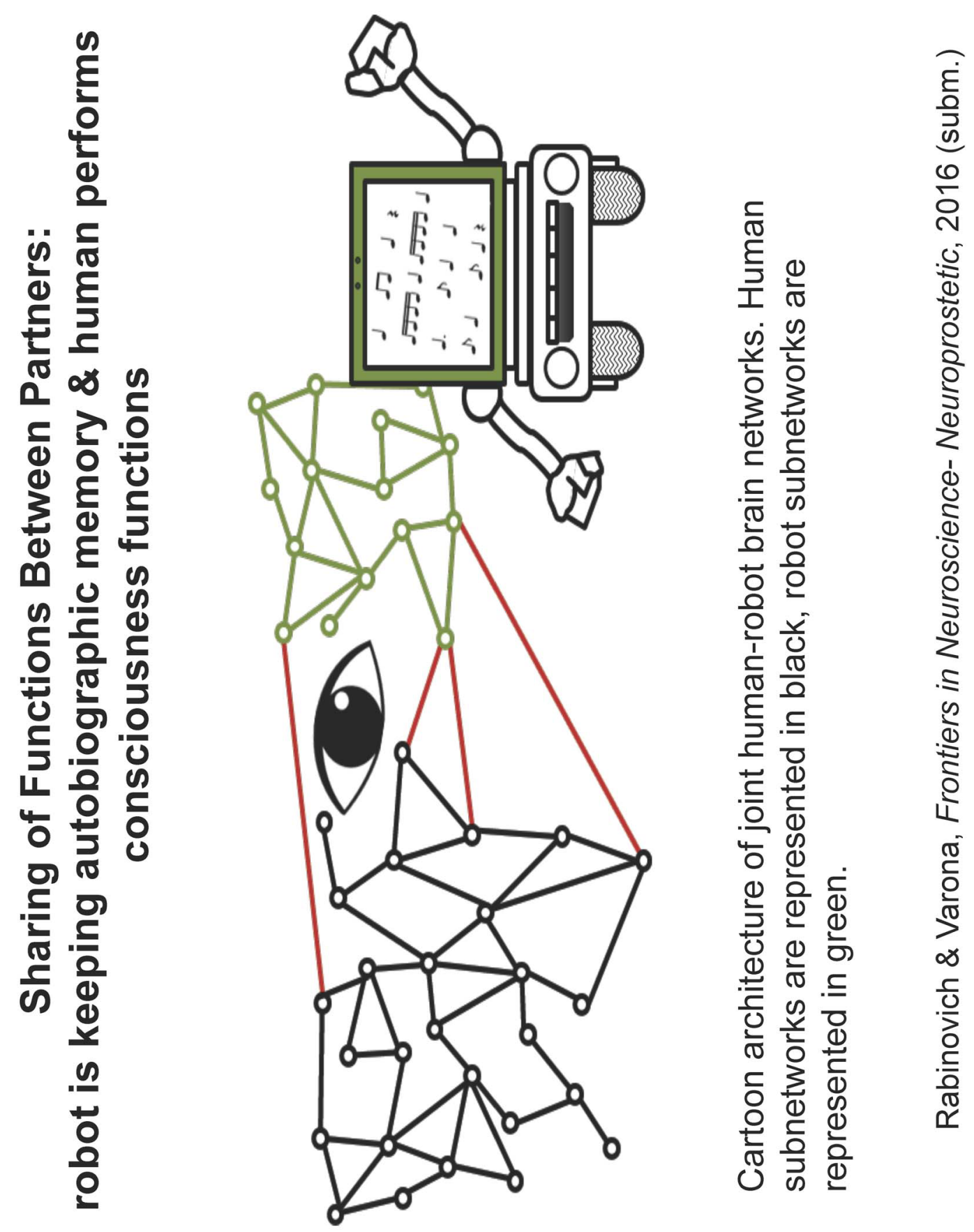


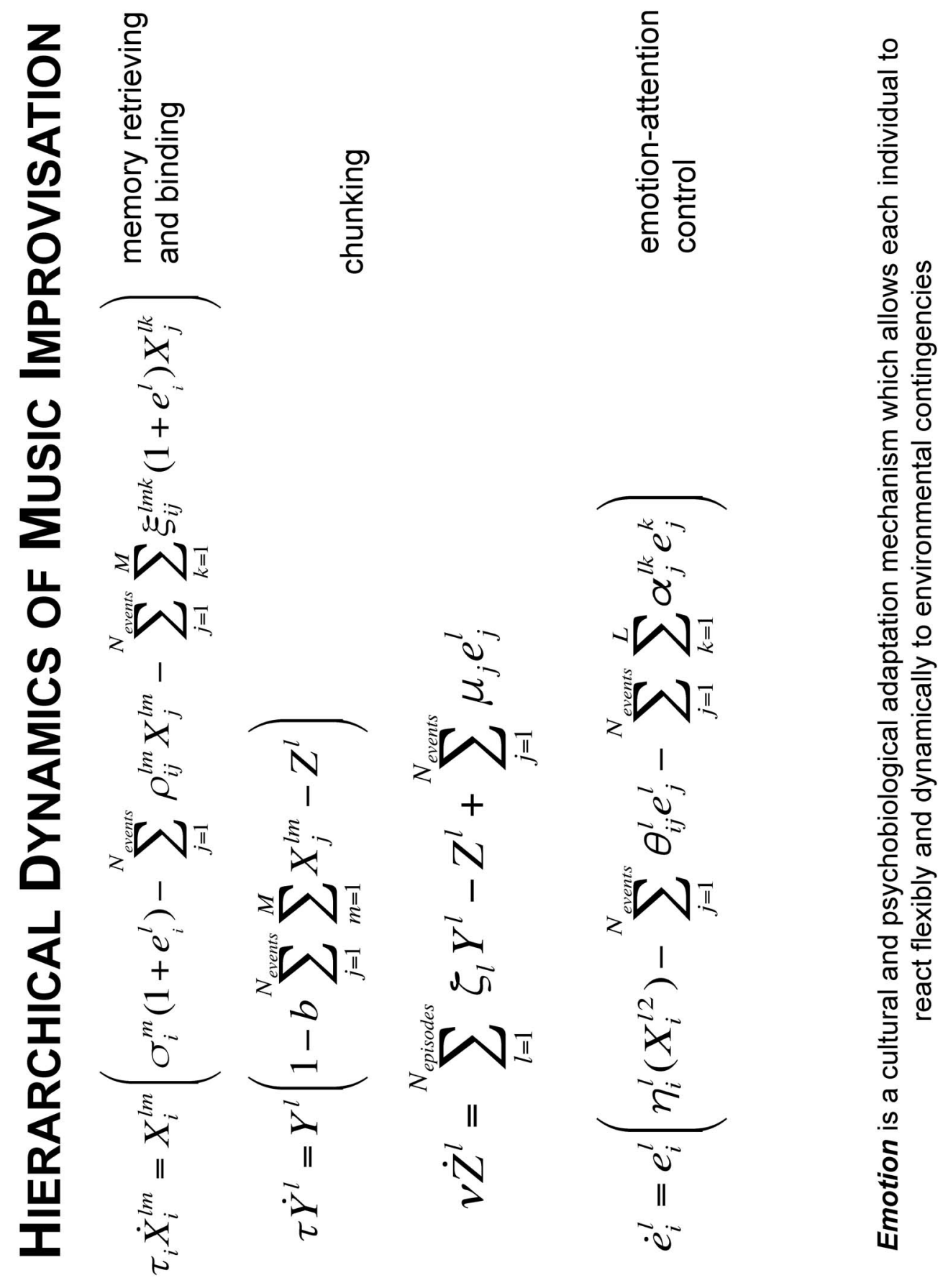




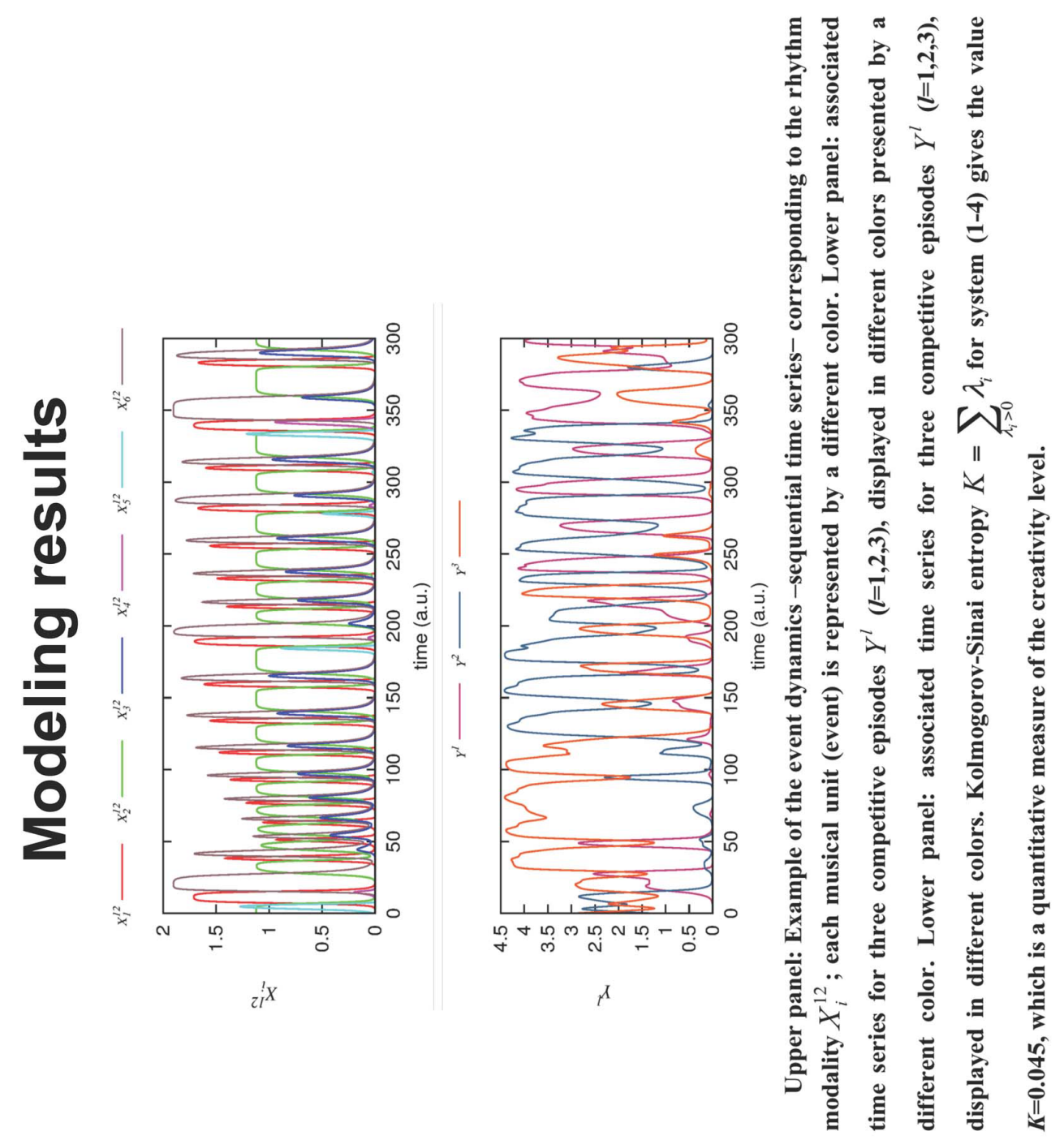

(C) М. Рабинович, П. Варона 


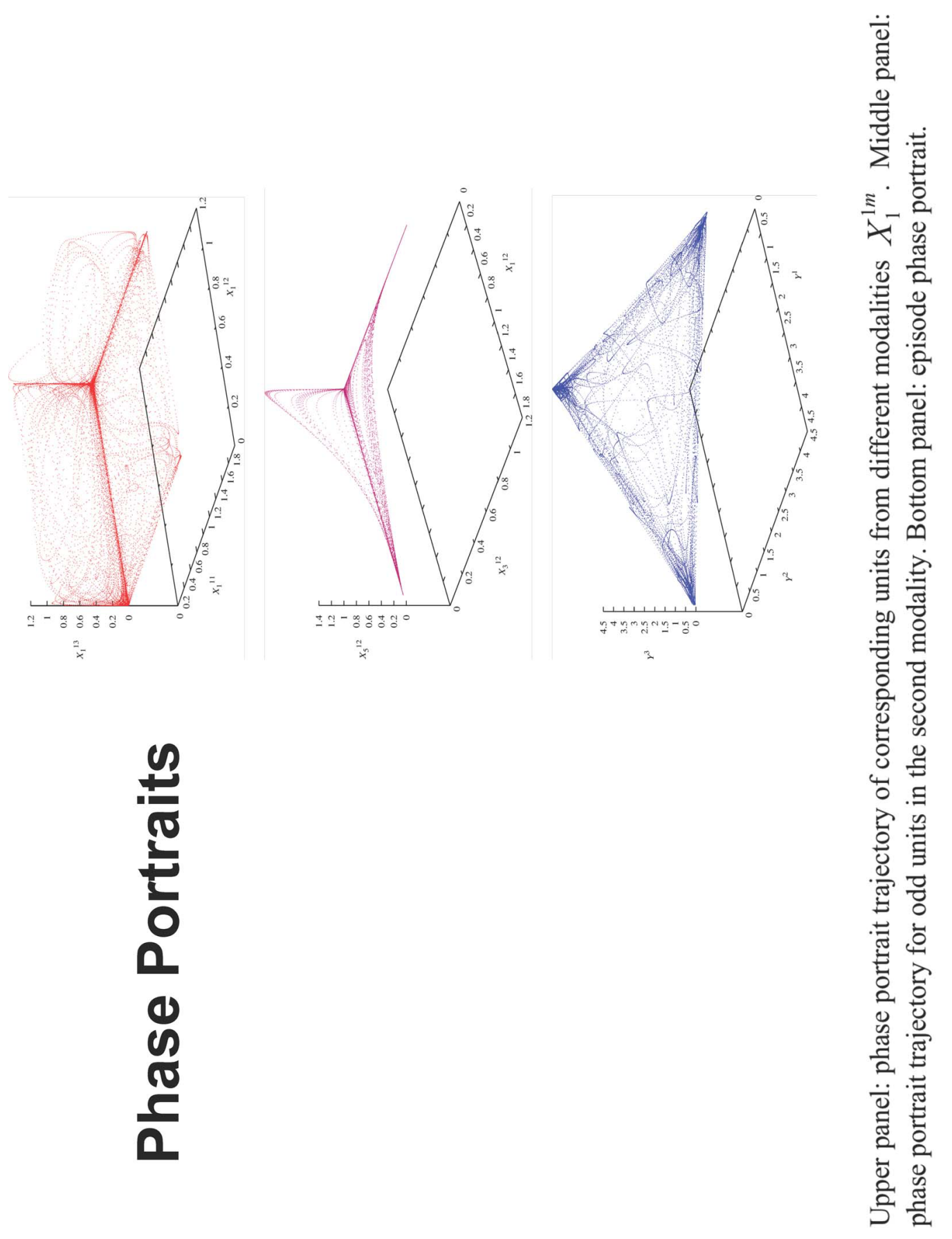




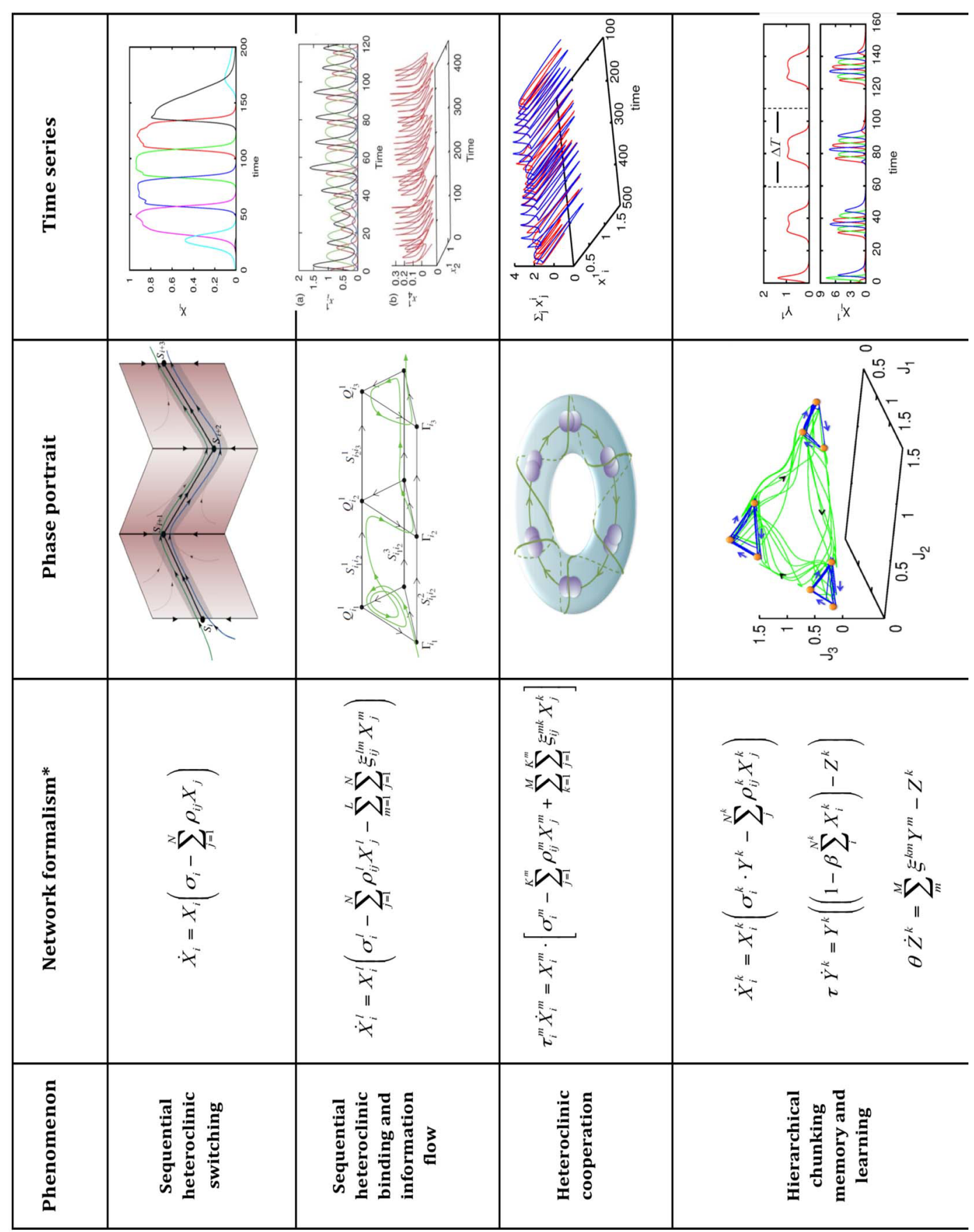




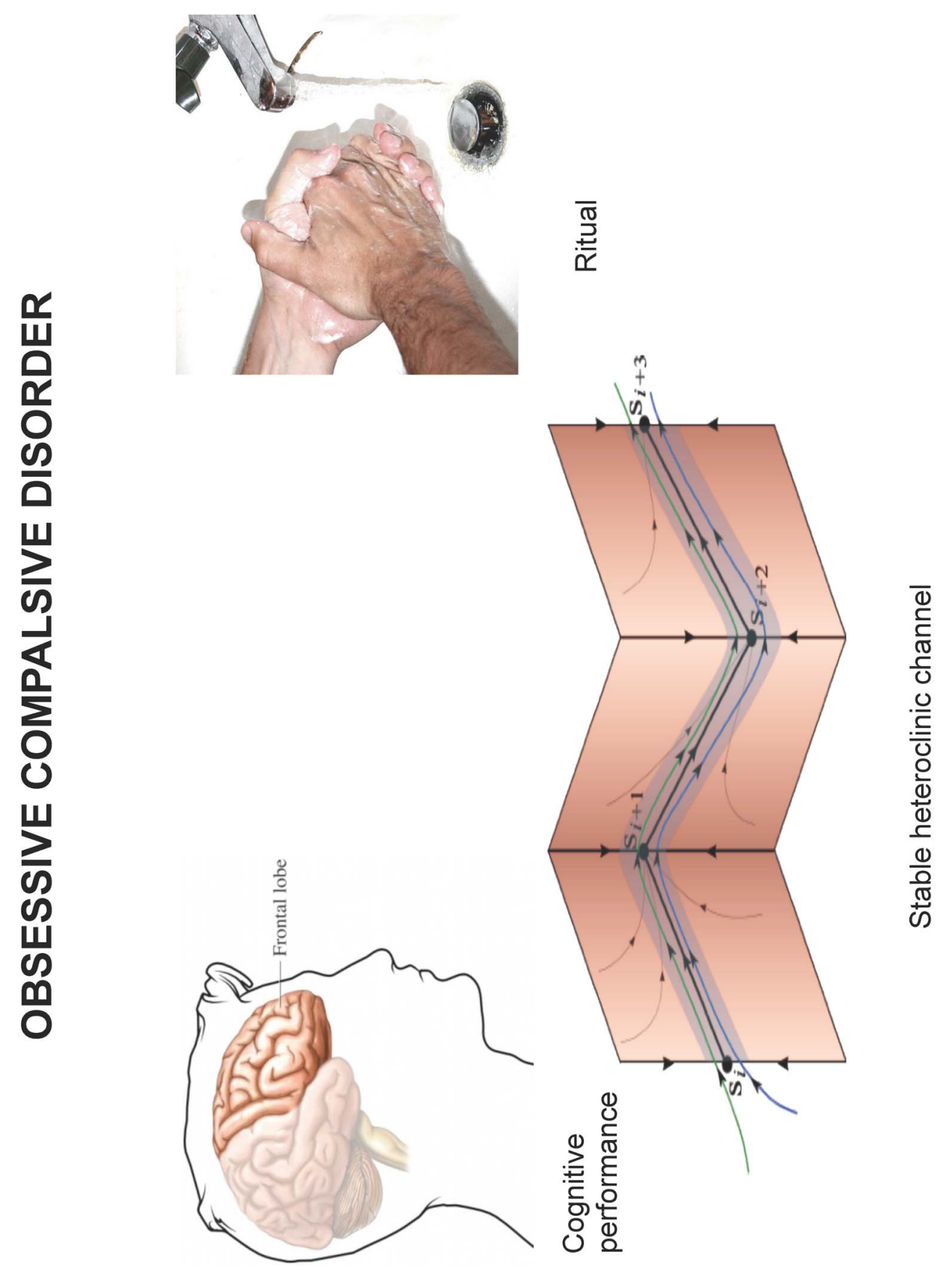

(C) М. Рабинович, П. Варона

Изв. вузов «ПНД», т. 25, № 3, 2017 

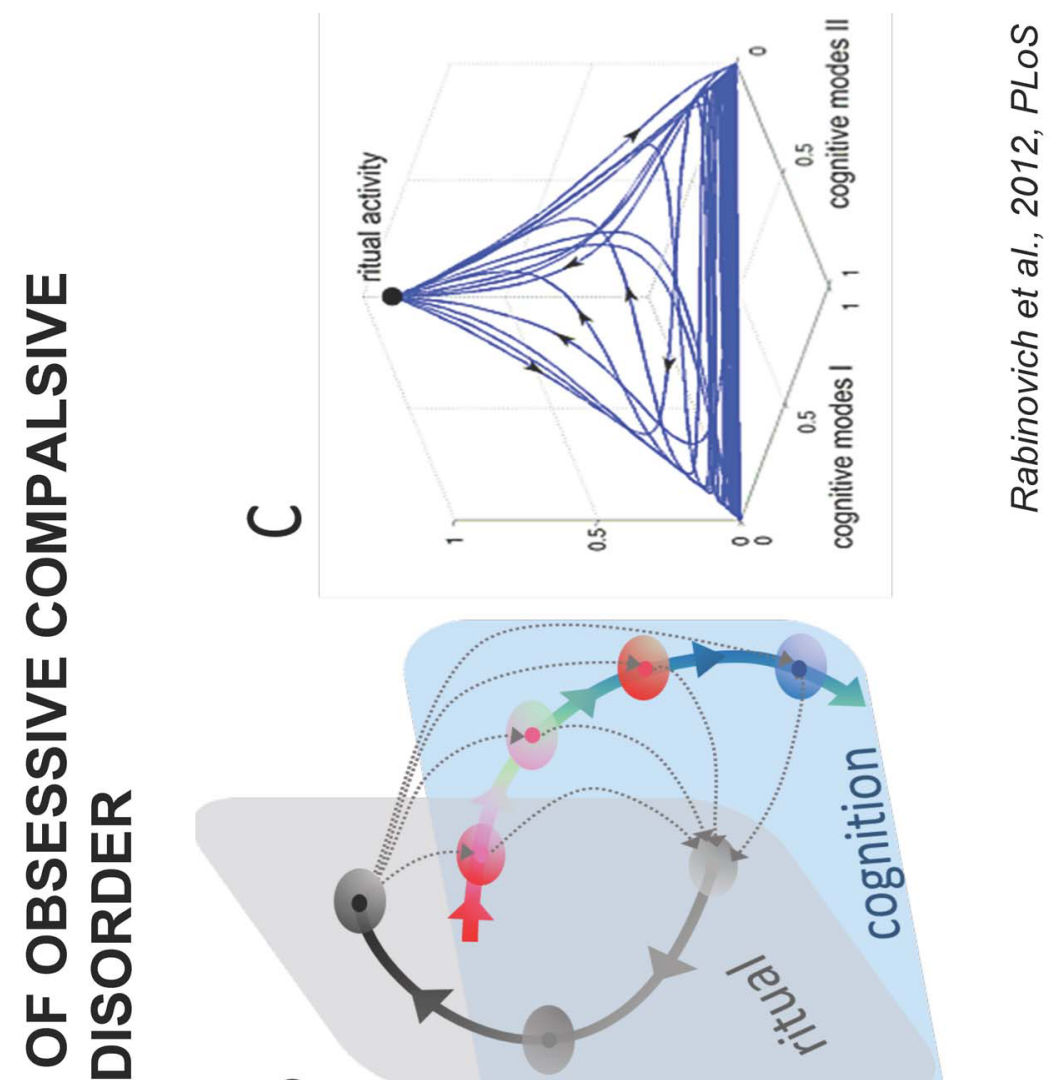

$\frac{1}{2}$

$\infty$

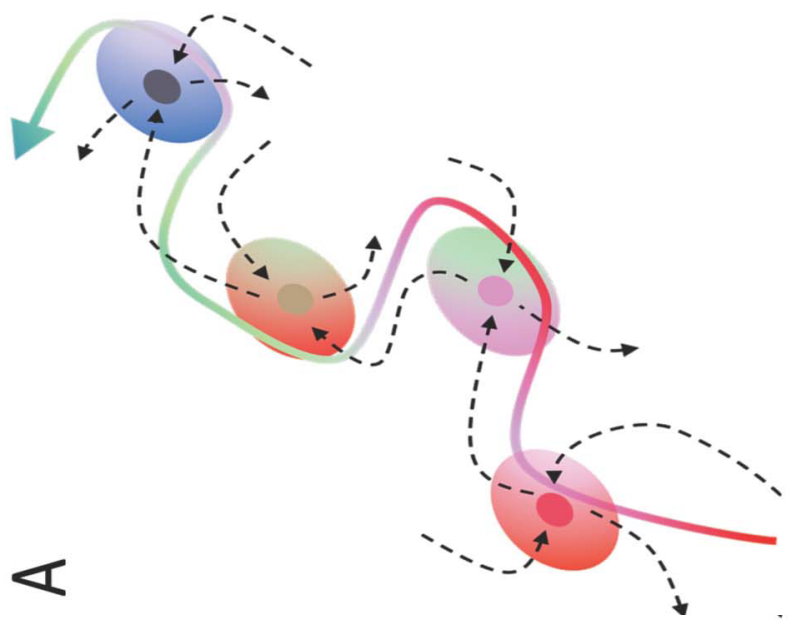

$\sum_{\text {U }}$
폰 
В дополнение к литературе, указанной на слайдах (см.References [1-28]), рекомендуем ознакомиться с недавними публикациями по данному направлению [29-48].

\section{References}

1. Rabinovich M.I., Simmons A.N., Varona P. Dynamical bridge between brain and mind. Trends in Cognitive Sciences. 2015. Vol. 19(8). Pp. 453-461.

2. Stokes M., Kusunoki M., Sigala N., Nili H., Gaffan D., Duncan J. Dynamic coding for cognitive control in prefrontal cortex. Neuron. 2013. Vol.78(2). Pp. 364-375.

3. Rabinovich M, Huerta R, Laurent G. Transient dynamics for neural processing. Science. 2008. Vol. 321(5885). Pp. 48-50.

4. Cunningham J.P., Yu B.M. Dimensionality reduction for large-scale neural recordings. Nature Neuroscience. 2014. DOI: 10.1038. nn.3776.

5. Rabinovich M., Volkovskii A., Lecanda P., Huerta R., Abarbanel H.D.I.; Laurent G. Dynamical encoding by networks of competing neuron groups: Winnerless competition. Physical Review Letters. 2001. Vol. 87(6): 068102.

6. Afraimovich V.S, Zhigulin V.P, Rabinovich M.I. On the origin of reproducible sequential activity in neural circuits. Chaos. 2004. Vol. 14(4). Pp. 1123-1129

7. Jones L.M., Fontanini A., Sadacca B.F., Miller P., Katz D. B. Natural stimuli evoke dynamic sequences of states in sensory cortical ensembles. PNAS. 2007. Vol. 104(47).

8. Limb C.J., Braun A.R. Neural substrates of spontaneous musical performance: An fMRI study of jazz improvisation. PLOS ONE. 2008. 3(2). doi:10.1371/journal.pone.0001679.

9. Fox M.D., Snyder A.Z., Vincent J.L., Corbetta M., Van Essen D.C., Raichle M.E. The human brain is intrinsically organized into dynamic, anticorrelated functional networks. PNAS. 2005. Vol. 102. Pp. 9673-9678.

10. Yuste R., Fairhall A.L. Temporal dynamics in fMRI resting state activity. PNAS. 2015. Vol. 112(17).

11. Spreng R.N, Sepulcre J., Turner G.R., Stevens W.D., Schacter D.L. Intrinsic architecture underlying the relations among the default, dorsal attention, and frontoparietal control networks of the human brain. J. Cogn. Neuroscience. 2013. Vol. 25. Pp. 74-86.

12. Barttfeld P., Uhrig L., Sitt J.D., Sigman M., Jarraya B., Dehaene S. Signature of consciousness in the dynamics of resting-state brain activity. PNAS. 2015. Vol. 112(3). Pp. 887-892.

13. Rabinovich M.I., Varona P., Tristan I., Afraimovich V.S. Chunking dynamics: Heteroclinics in mind. Frontiers in Computational Neuroscience. 2014. Vol. 8(22).

14. Rabinovich MI, Afraimovich VS, Varona P. Heteroclinic binding. Dynamical Systems. 2010. Vol. 25(3). Pp. 433-442.

15. Rabinovich M.I., Muezzinoglu M.K., Strigo I., Bystritsky A. Dynamical principles of emotion-cognition interaction: mathematical images of mental disorders. PLOS ONE. 2010. Vol. 5(9): e12547.

16. Rabinovich M.I., Muezzinoglu M.K. Nonlinear dynamics of the brain: Emotion and cognition. Physics-Uspekhi. 2010. Vol. 53(4). Pp. 357-372.

17. Muezzinoglu M.K., Tristan I., Huerta R., Afraimovich V.S., Rabinovich M.I. Transient versus attractors in complex networks. International Journal of Bifurcation and Chaos. 2010. Vol. 20(6). Pp. 1-23.

18. Muezzinoglu M.K., Vergara A., Huerta R., Rabinovich M.I. A sensor conditioning principle for odor identification. Sensors and Actuators B-Chemical. 2010. Vol. 146. Pp. $472-476$. 
19. Bick C., Rabinovich M.I. On the occurrence of stable heteroclinic channels in LotkaVolterra models. Dynamical Systems. 2010. Vol. 25. Pp. 95-110.

20. Rabinovich M.I., Tristan I., Varona P. Hierarchical nonlinear dynamics of human attention. Neuroscience and Biobehavioral Reviews. 2015. Vol. 55. Pp. 18-35.

21. Rabinovich M.I., Tristan I., Varona P. Neural dynamics of attentional cross-modality control. PLOS ONE. 2013. Vol. 8(5): e64406.

22. Varona P., Rabinovich M.I. Hierarchical dynamics of informational patterns and decisionmaking. Proceedings of the Royal Society of London B: Biological Sciences. 2016. Vol. 283 (1832): 20160475. DOI: 10.1098/rspb.2016.0475.

23. Lu J., Yang H., Zhang X., He H., Lu C., Yao D. The brain functional state of music creation: an fMRI study of composers. Scientific Reports. 2015. Vol. 5:12277

24. Rabinovich M.I., Huerta R., Afraimovich V.I. Dynamics of sequential decision making. Phys. Rev Lett. 2006. Vol. 97(18): 188103.

25. Rabinovich M.I., Huerta R., Varona P. Heteroclinic synchronization: ultrasubharmonic locking. Phys Rev Lett. 2006. Vol. 96(1): 014101.

26. Rabinovich M.I., Varona P. Frontiers in neuroscience-neuroprosthetic. 2016 (paper submitted.)

27. Rabinovich M.I., Afraimovich V.S., Bick C., Varona P. Information flow dynamics in the brain. Physics of Life Reviews. 2012. Vol. 9(1). Pp. 51-73.

28. Rabinovich M.I., Afraimovich V.S., Bick C., Varona P. Instability, semantic dynamics and modeling brain data. Physics of Life Reviews. 2012. Vol. 9(1). Pp. 80-83.

29. Jun Tani. Exploring Robotic Minds: Actions, Symbols, and Consciousness as Self Organizing Dynamic Phenomena. Oxford University Press, 2017.

30. Barron A.B., Klein C. What insects can tell us about the origins of consciousness. PNAS. 2016. May 3. Vol. 113, No. 184900-4908.

31. Key B., Arlinghaus R., Browman H.I. Insects cannot tell us anything about subjective experience or the origin of consciousness. PNAS. 2016. July 5. Vol.113, No. 27E3813.

32. Koch C., Massimini M., Boly M., Tononi G. Neural correlates of consciousness: Progress and problems. Nat. Rev. Neurosci. 2016. Apr. Vol. 17, No. 5, Pp. 307-321.

33. Dehaene S., Consciousness and the Brain: Deciphering How the Brain Codes Our Thoughts. Penguin, 2014.

34. Dehaene S., Charles L., King J.R., Marti S. Toward a computational theory of conscious processing. Curr. Opin. Neurobiol. 2014. Vol. 25. Pp. 76-84.

35. Varona P., Rabinovich M.I. Hierarchical dynamics of informational patterns and decision making. Proc. R. Soc. B. 2016. Vol. 283. P. 20160475.

36. Beaty R.E., Benedek M., Silvia P.J., Schacter D.L. Creative cognition and brain network Dynamics. Trends Cogn. Sci. 2016. Vol. 20, No. 2. Pp. 87-95.

37. Schurger A., Gale S., Gozel Olivia, Blanke Olaf. Performance monitoring for braincomputer-interface actions. Brain and Cognition. 2017. Feb. Vol. 111. Pp. 44-50.

38. Sharma Shivani, Babu Nandita. Interplay between creativity, executive function and working memory in middle-aged and older adults. Creativity Research Journal. 2017. Vol 29. Pp. 71-77.

39. Silva Rui, Louro Luís, Malheiro Tiago, Erlhagen Wolfram, Bicho Estela. Combining intention and emotional state inference in a dynamic neural field architecture for humanrobot joint action. Adaptive Behavior. 2016. Vol. 24(5). Pp. 350-372.

40. Beaty R.E., Silvia P.J., Benedek M. Brain networks underlying novel metaphor produc- 
tion. Brain and Cognition. 2017. Vol. 111. Pp. 163-170.

41. First M., Williams J., Karg R., Spitzer R. Structured clinical interview for DSM5. Research Version. SCID-5 for DSM-5, Research Version (SCID-5-RV). American Psychiatric Association. Arlington, VA, 2015.

42. Rabinovich M.I., Simmons A.N., Varona P. Dynamical bridge between brain and mind. Trends Cogn. Sci. 2015. Vol. 19, No. 8. Pp. 453-461.

43. Rabinovich M.I., Sokolov Y., Kozma R. Robust sequential working memory recall in heterogeneous cognitive networks. Front. Syst. Neurosci. 2014. Jan. Vol. 8. P. 220.

44. Rabinovich M.I., Varona P. Functional dynamical networks in joint human-robot creativity. Front. Comput. Neurosci. 2017 (paper submitted).

45. Barttfeld P., Uhrig L., Sitt J.D., Sigman M., Jarraya B., Dehaene S. Signature of consciousness in the dynamics of resting-state brain activity. Proc. Natl. Acad. Sci. U.S.A. 2015. Jan. Vol. 112, No. 3. Pp. 887-892.

46. Lu J., Yang H., Zhang X., He H., Luo C., Yao D. The brain functional state of music creation: An fMRI study of composers. Sci. Rep. 2015. Jan. Vol. 5. P. 12277.

47. Bajaj S., Adhikari B. M., Friston K. J., Dhamala M. Bridging the gap: Dynamic causal modeling and granger causality analysis of resting state functional magnetic resonance imaging. Brain Connect. 2016. Jan. Vol. 6, No. 8. Pp. 652-661.

48. Andrews-Hanna J.R., Smallwood J., Spreng R.N. The default network and self-generated thought: Component processes, dynamic control, and clinical relevance. Ann. N.Y. Acad. Sci. 2014. 1316. Pp. 29-52.

Поступила в редакичию
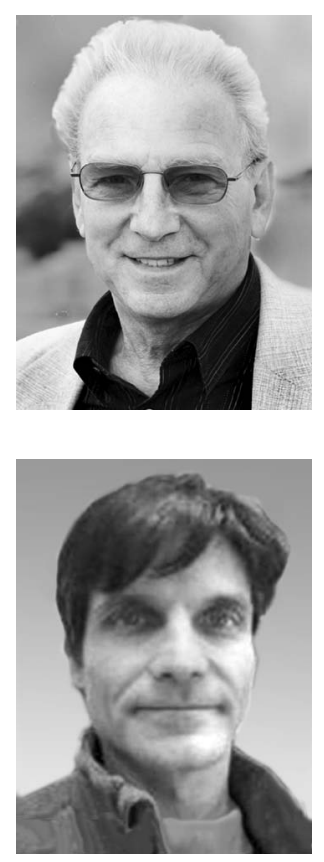

Михаил Израилевич Рабинович (род. 20 апреля 1941, Горький, Горьковская область, РСФСР) - советский и американский учёный-физик, доктор физикоматематических наук, специалист по теории колебаний и волн, динамическому хаосу и теории турбулентности, физике классических нелинейных полей. Пишет стихи. Доктор физ.-мат. наук (1974), профессор (1980), чл.-корр. АН СССР (1991). В 1990 работал в качестве приглашенного профессора в Чикагском университете, с 1991 - профессор Калифорнийского университета в Сан-Диего. Основатель и Президент Международного центра Перспективных Исследований (Нижний Новгород, 1994-2002). С 2004 года живет в США. Область научных интересов - прикладная математика, динамический хаос и теория турбулентности, нелинейная динамика классических полей, нейродинамика и динамика когнитивных процессов. Автор более двухсот научных работ и пяти монографий.

US, UCSD, 9500 Gilman Drive, La Jolla, CA 92093-0328

BioCircuits Institute

E-mail: mrabinovich@gmail.com

Pablo Varona received his degree in Theoretical Physics in 1992 and the $\mathrm{PhD}$ in Computer Science in 1997 from Universidad Autonoma de Madrid (UAM). He was a postdoc and later an assistant research scientist at the Institute for Nonlinear Science, University of California, San Diego. Since 2002 he is an associate professor at the Escuela Politecnica Superior, UAM. Among his main research interests are transient dynamics in neural systems, the design of novel activity-dependent stimulation protocols for neuroscience research, and bio-inspired neural networks, robotics and devices.

C Francisco Tomás y Valiente, 11, 28049 Madrid, Spain

Universidad Autónoma de Madrid

E-mail: pablo.varona@uam.es

(с) М. Рабинович, П. Варона

Изв. вузов «ПНД», т. 25, № 3, 2017 